\title{
Propagation Characteristics of Shock Waves Driven by Gaseous Detonation Waves
}

\author{
Shinpei Kato ${ }^{*}$, Satoru Hashimoto ${ }^{*}$, Akane Uemichi ${ }^{*}$, Jiro Kasahara ${ }^{\dagger}$ \\ University of Tsukuba, Ibaraki 305-8573, Japan \\ and \\ Akiko Matsuo ${ }^{\ddagger}$
}

Keio University, Kanagawa 223-8522, Japan

Presented at 22nd ICDERS in July 2009

Keywords Shock Wave, Detonation, PDE, Optical Visualization, SPL

\begin{abstract}
We experimentally investigated propagation characteristics of the shock wave driven by a gaseous detonation wave emerging from the open end of a cylindrical detonation tube. In the present study, we visualized the shock wave and exhaust flowfields using a shadowgraph optical system and we obtained peak overpressure in the tube axial direction and the continuous shape transformation of shock waves around the tube open end. We also obtained overpressure histories of the shock wave using piezo-pressure transducers within $201 \mathrm{~m}$ from the open end of the tube. We normalized and classified these results by four regions using non-dimensional pressure and distance which are independent of variety of mixture and tube diameter. In the vicinity of the open end of the tube, the shock wave is nearly planar and does not significantly attenuate, and the peak overpressure maintains approximately C-J pressure. Subsequently, the shock wave attenuates rapidly, transforming from quasispherical to spherical. Farther from the tube open end, the shock wave propagates with approximately sound characteristic so that the peak overpressure decreases proportional to $1 / r$. Eventually, the shock wave begins to attenuate more rapidly than ideal sound attenuation, which may be due to the viscous effect.
\end{abstract}




\footnotetext{
* Graduate Student, Department of Engineering Mechanics and Energy

${ }^{\dagger}$ Associate Professor, Department of Engineering Mechanics and Energy, Senior Member AIAA

${ }^{\ddagger}$ Professor, Department of Mechanical Engineering, Member AIAA
}

\begin{tabular}{|c|c|}
\hline & Nomenclature \\
\hline$D$ & $=$ tube inner diameter \\
\hline$L$ & $=$ tube length \\
\hline$r$ & $=$ distance from the tube open end \\
\hline$r_{\mathrm{v}}$ & $=$ axial distance of an observed region \\
\hline$W_{\mathrm{d}}$ & $=$ characteristic explosion length in Piston Model \\
\hline$W_{\mathrm{s}}$ & $=$ scaling length in Constant Energy Efflux Model \\
\hline $\mathrm{R}_{\mathrm{d}}$ & $=$ normalized distance in Piston Model \\
\hline $\mathrm{R}_{\mathrm{s}}$ & = normalized distance in Constant Energy Efflux Model \\
\hline$p$ & $=$ peak pressure of a shock wave in tube axial direction \\
\hline$p_{0}$ & = initial pressure of mixture filling a tube \\
\hline$p_{\mathrm{CJ}}$ & $=$ pressure at $\mathrm{C}-\mathrm{J}$ state \\
\hline$p_{\mathrm{e}}$ & $=$ pressure at a tube exit \\
\hline$p_{\text {atm }}$ & $=$ ambient pressure \\
\hline$u$ & $=$ particle velocity \\
\hline$u_{\mathrm{CJ}}$ & $=$ particle velocity at C-J state \\
\hline$u_{\mathrm{e}}$ & $=$ particle velocity at a tube exit \\
\hline$\rho_{\mathrm{e}}$ & $=$ density at a tube exit \\
\hline$T_{\mathrm{CJ}}$ & $=$ temperature at C-J state \\
\hline
\end{tabular}




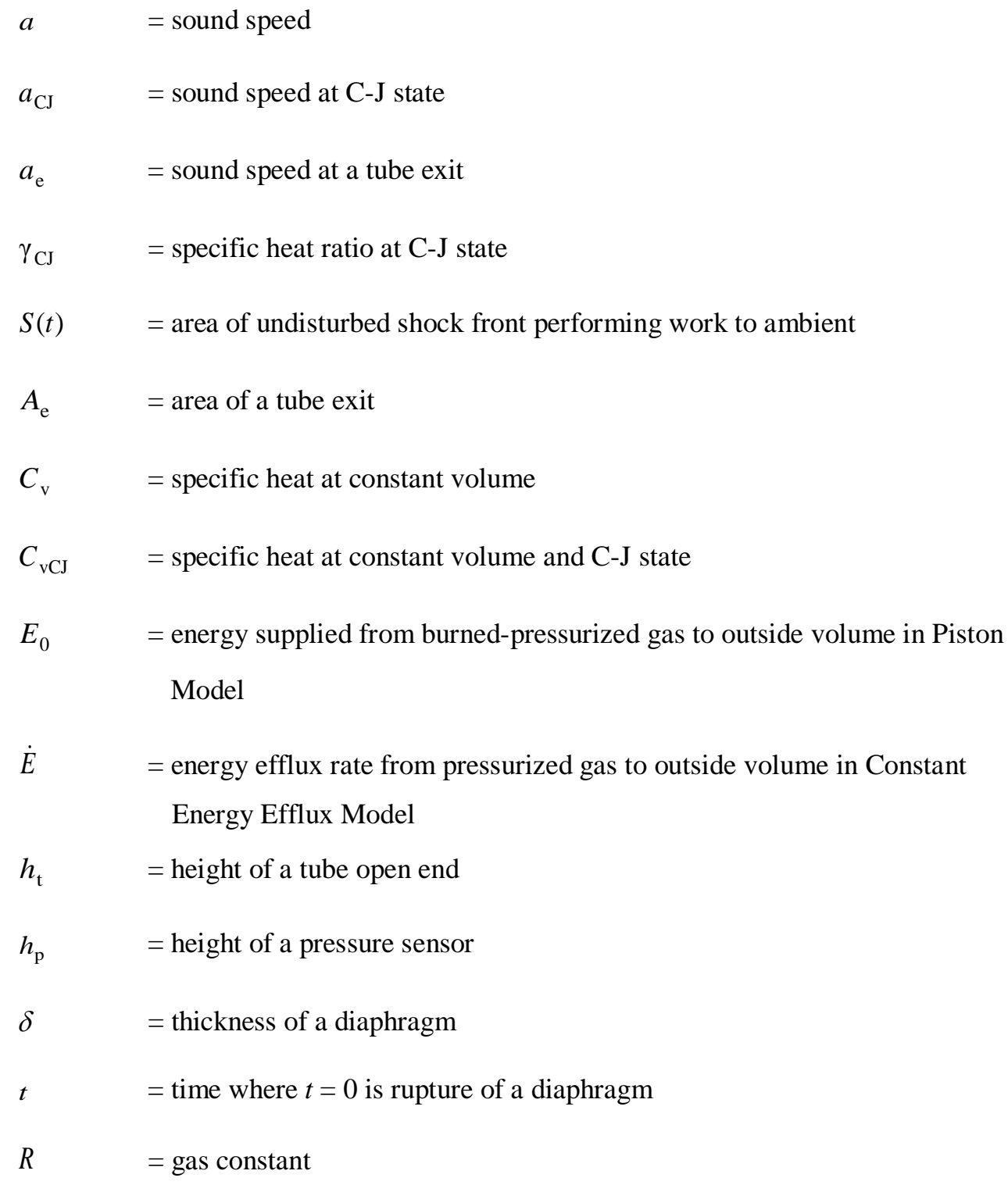




\section{Introduction}

We experimentally investigated propagation characteristics of the shock wave driven by a gaseous detonation wave emerging from a cylindrical detonation tube where one end is closed and the other is open, which is well- known as a typical combustor for pulse detonation engines (PDEs) as described in several review papers [1, 2, 3 and 4]. Many experimental, computational, and analytical works have focused on PDEs. Kasahara et al. [5] fabricated and tested a pulse detonation rocket and also validated their model which predicts the thrust generated. Endo and Fujiwara [6] analyzed the performance of a straight-tube PDE fully filled with propellant, and formulated the pressure history at the thrust wall of the closed end of the PDE tube with no empirical parameters. In a subsequent study, Endo et al. [7] formulated more accurately the pressure decay portion of this thrust-wall pressure history. Recently, Endo et al. [8] proposed a single-cycle partially filled PDE performance model. Kasahara et al.[9] experimentally carried out thrust measurements of a multi-cycle partially filled pulse detonation rocket engine (PDRE). On the other hand, Kasahara et al. [10] simulated impulse generation of an open-ended PDE using an open-ended shock tube in a safe experimental environment.

The motivation behind the present study was to investigate the sound pressure level (SPL) of the shock wave for creating safer experimental environments for PDEs development. In general, shock waves are generated by solid explosives or shock tube, but they can also be generated using a detonation wave that propagates at from 2 to $3 \mathrm{~km} / \mathrm{s}$ (gaseous-detonation-drive) through combustible gas. Pulsating gaseous detonation makes it possible to periodically generate shock waves in unconfined space at high frequency. The shock generating process by gaseous detonation is composed of five major steps. First, a detonable mixture is supplied to the detonation tube. Second, energy is supplied to the detonable mixture filling the detonation tube, for instance, by ignition with an automotive spark plug. Third, a self-sustained detonation wave begins to propagate from near the closed end of the tube toward the open end of the tube and also produces burned-pressurized gas behind the detonation wave. Fourth, when the detonation wave emerges from the open end of the tube, the burned-pressurized gas produced behind 
the detonation wave compresses ambient gas in unconfined space and creates a shock wave. Finally, the burned-pressurized gas within the tube begins to be exhausted and the tube inner pressure eventually decreases to ambient pressure. This process can be periodically repeated at high frequency.

To utilize the shock wave, we must investigate the characteristics of its propagation. Many works related to blast waves have been published, including those by Brossard et al. [11, 12 and 13], Sénégas et al. [14], Tang et al. [15, 16], Ismail et al. [17, 18], and Held et al. [19]. Fansler et al. [20] investigated the muzzle blast overpressure. Schmidt et al. [21] and Bertrand et al. [22] experimentally investigated overpressure of shock waves emerging from an open-ended shock tube depending on the distance from the tube open end. Although the detonation tube is similar to the open-ended shock tube as an experimental apparatus, the phenomenon itself is totally different and the pressure profile behind a detonation wave within the detonation tube is significantly different from the pressure profile behind a shock wave emerging from the open-ended shock tube. In related work, Sochet et al. [23, 24 and 25] and Vaglio et al. [26] experimentally investigated overpressure of a shock wave emerging from the detonation tube depending on the distance from the tube open end, while Allgood et al. [27] computationally simulated the flowfield following a shock wave emerging from a tube open end. Sochet et al. [23, 24 and 25] showed that peak overpressure of the shock wave in the tube axial direction is highly dependent on the tube diameter, exit pressure, exit particle velocity, and exit sound speed. In addition, they experimentally defined an energy supply relation from the burned-pressurized gas to ambient gas. Glaser et al. [28] investigated the relation between the detonation wave speed and equivalence ratio and the relation between the detonation wave speed and fill fraction using shadowgraph visualization. In our previous study [29] and the present study, we also performed shadowgraph visualization around the tube open end to investigate the relationship between peak overpressure of a shock wave in the tube axial direction and its wave shape around the open end of the tube. In the far field from the open end of the tube, we obtained overpressure histories of shock waves using piezo-pressure sensors, because we believe that the longer distance a shock wave propagates, the 
more viscous effect should be observed in its peak overpressures. The results obtained were organized using non-dimensional distance and pressure as proposed by Sochet et al. [24].

\section{Experimental details}

\section{A. Shadowgraph optical visualization}

In the near field from the tube open end, we set up a shadowgraph system so that we could observe around the tube end, where the horizontal axis of the detonation tube crossed the optical axis of the shadowgraph system, as shown in Figure 1. As shown in Table 1, the detonable mixture used was $\mathrm{C}_{2} \mathrm{H}_{4}+3 \mathrm{O}_{2}$, and the initial pressure was approximately $1 \mathrm{~atm}$. The detonable mixture had been premixed, and we had provided at least 72 hours for diffusive mixing prior to the experiments. In the experiments, we used two kinds of detonation tubes, one with 27-mm inner diameter and 1200-mm length (Tube C) and the other with 27-mm inner diameter 6400-mm length (Tube D). There was an automotive spark plug (NGK D8HA) at the closed end of each detonation tube. The Mylar diaphragm of $\delta=12 \mu \mathrm{m}$ thickness (in Shot 1 ) or $\delta=1.5 \mu \mathrm{m}$ thickness (in Shot 2-11) was used to separate the detonable mixture inside the tube from atmospheric air outside the tube. $r_{\mathrm{v}}$ denotes the axial distance of an observed region, which was mainly varied so we could observe shock waves propagating in a wide range of unconfined space. $T_{\text {atm }}$ denotes the ambient temperature, which was maintained between approximately $293.5 \mathrm{~K}$ and $301.2 \mathrm{~K}$. $p_{\text {atm }}$ denotes atmospheric pressure. $T_{\mathrm{CJ}}, p_{\mathrm{CJ}}$, and $u_{\mathrm{CJ}}$ denote temperature, pressure, and particle velocity at the C-J state respectively, which were computed with AISTJAN (Thermochemical Database of Gases and Condensed Materials) [30]. The high-speed video camera used was a Hyper Vision HPV-1 (Shimadzu Co., Ltd.) of which the minimum interframe time is $1 \mu \mathrm{s}$ and the minimum exposure time is $250 \mathrm{~ns}$.

\section{B. Overpressure measurement with pressure sensors}

In the far field from the open end of the tube, as shown in Figure 2, we carried out overpressure measurements at $r=1,10,20,30,98.5$, and $201 \mathrm{~m}$ from the open end of the tube. In a series of far-field 
experiments, as listed on Table 2, we mostly used the detonation tube with $D=50 \mathrm{~mm}$ and $L=1200$ mm (Tube A), where $D$ and $L$ denote the tube inner diameter and tube length respectively. However, note that we also carried out experiments using two different sizes of a tube (Tube B: $D=50 \mathrm{~mm}, L=$ $2400 \mathrm{~mm}$, Tube C: $D=27 \mathrm{~mm}, L=1200 \mathrm{~mm})$ at $r=10 \mathrm{~m}$ only to compare overpressures using various tube inner diameters and tube lengths (Shot 18, 20, 21), because, according to Sochet et al. [24], the supplied energy to outside volume is more dependent on tube diameter rather than tube length in the vicinity of a tube. Hence we needed to investigate the applicability assessment in terms of the distance from the open end of the tube.

In the experiments at 20, 30, 98.5, and $201 \mathrm{~m}$, only Tube A was used as listed on Table 2. The Mylar diaphragm used had $\delta=12 \mu \mathrm{m}$ thickness. The pressure sensors used were 137A23 (Shot 12-15) and M106B52 (Shot 16-21) manufactured by PCB Piezotronics, Inc. Pressure gauge itself in the sensor 137A23 is originally in pencil-like body in order to diminish disturbance generation when a shock wave passes around a sensor. The edge of pencil-like body faces a source of explosion such as a tube exit and the pressure gauge obtains pressure on a side wall of pencil-like body so that the pressure gauge is pressurized only by static pressure of a pressure wave. As for the sensor M106B52, pressure gauge was installed within a pencil-like body as well that we designed and fabricated.

Additionally, as shown in Figure 2, our experiments are classified in three groups C1, C2, and C3 according to their configurations. C1 is the configuration with $h_{\mathrm{t}}=0.5 \mathrm{~m}$ and $h_{\mathrm{p}}=0.5 \mathrm{~m}$, where $h_{\mathrm{t}}$ and $h_{\mathrm{p}}$ denote the height of the tube and the height of the pressure sensor from the ground surface, respectively. It simulates the experiments at $r=1,10,20$, and $30 \mathrm{~m}$ (Shot 12,13,14, 15). C2 is the case with $h_{\mathrm{t}}=1.0$ $\mathrm{m}, h_{\mathrm{p}}=1.0 \mathrm{~m}$, in which there is a reflected wave with approximately $0.5 \mathrm{~ms}$ delay. It simulates the experiments at $r=98.5 \mathrm{~m}$ (Shot 16). C3 is the case $h_{\mathrm{t}}=0.5 \mathrm{~m}$ and $h_{\mathrm{p}}=7$ or $47 \mathrm{~m}$. It is the configuration in which a reflected wave has approximately $4 \mathrm{~ms}$ delay and simulates the experiment at $r=201 \mathrm{~m}$ (Shot 17).

Because the effect that a reflected wave from ground surface has on peak overpressure of an incident shock is dependent on the configuration shown in Figure 3, we carried out additional experiments to 
estimate the effect (Shot 18, 19), in which $h_{\mathrm{t}}$ and $h_{\mathrm{p}}$ are varied to observe an independent incident shock from a reflected wave, compared the difference in peak overpressure depending on the configuration at $r=10 \mathrm{~m}$ (Shot 12, 18, 19) as listed on Table 2.

\section{Non-dimensional parameters}

For obtained results, we normalized the overpressure and the axial distance from the tube open end. Normalized overpressure is determined based on the following relation:

$$
\mathrm{P}=\frac{p-p_{\text {atm }}}{p_{\mathrm{atm}}}
$$

where $p$ and $p_{\text {atm }}$ denote the absolute peak pressure of the shock wave and the ambient air pressure, respectively. Normalized distance is determined using the following equation:

$$
\mathrm{R}_{\mathrm{d}}=\frac{r}{W_{\mathrm{d}}}
$$

where $r$ is the distance from the tube open end in the tube axial direction, and $W_{\mathrm{d}}$ is the characteristic explosion length given by $W_{\mathrm{d}}=\sqrt[3]{\left(E_{0} / p_{\text {atm }}\right)}$ in the spherical symmetry condition. $E_{0}$ denotes the energy supplied to outside volume, not just the chemical energy of the mixture, and to determine it we employed the following equation:

$$
E_{0}=\frac{\pi}{3.47} \frac{p u D^{3}}{a}
$$

where $D$ is the inner diameter of the tube and $p, u, a$ denote the absolute pressure, the particle velocity, and the sound speed at the tube open end. We used $p_{\mathrm{CJ}}, u_{\mathrm{CJ}}, a_{\mathrm{CJ}}$ as the conditions at the open end of the tube. This relation was originally proposed by Sochet et al. [24] and is based on the Piston Model presented in their study. As shown in Figure 4, the contact surface between the ambient gas (air) and burned-pressurized gas produced by a detonation wave compresses the ambient gas and continuously performs work on the ambient gas, creating a shock wave. However, the created shock front is composed of not only an undisturbed shock front with nearly same pressure as the exiting burned- 
pressurized gas but also of a diffracting shock front with lower pressure. In the model, they assumed that only the undisturbed shock front, of which area continuously diminishes as the expansion wave propagates perpendicular in the shock propagating direction, continuously performs work on the ambient gas with constant pressure given as the exit condition. In earlier study, we also mention experiments using an open-ended shock tube performed by Schmidt et al. [21]. They organized their results using the following scaling length:

$$
\mathrm{R}_{\mathrm{s}}=\frac{r}{W_{\mathrm{s}}}
$$

where $W_{\mathrm{s}}=\sqrt{\dot{E} /\left(p_{\text {atm }} a_{\text {atm }}\right)}$ is the scaling length and $\dot{E}$ is the rate of energy efflux from the exit of the shock tube, defined as follows:

$$
\dot{E}=\rho_{\mathrm{e}} u_{\mathrm{e}} A_{\mathrm{e}}\left[C_{v} T_{\mathrm{e}}+\frac{u_{\mathrm{e}}^{2}}{2}\right]
$$

Here, $\rho_{\mathrm{e}}, u_{\mathrm{e}}, T_{\mathrm{e}}$ denote the density, particle velocity, and temperature at the tube open end, respectively, and $A_{\mathrm{e}}$ and $C_{v}$ denote the area of the tube open end and specific heat at a constant volume, respectively. Note that the relation contains the assumption that the rate of energy efflux from the exit is constant (Constant Energy Efflux Model). The values calculated by the above equations and the exit conditions are shown in Table 3.

\section{Results and discussion}

In Figure 5, we show the shadowgraph images obtained in shot 1 in which the observation region is $r_{\mathrm{v}}$ $=15-70 \mathrm{~mm}$. Note that the images are color-reversed for convenience so that the current white portion was originally a black pattern and the current black portion was originally a white pattern. Figure 5-(a), (b), (c), (d), (e), (f), (g), and (h) show the shock wave at $t=4,8,12,16,20,24,28$, and $32 \mu \mathrm{s}$, respectively, where the rupture of the diaphragm is taken as $t=0 \mu \mathrm{s}$. The shock front seems to be gradually changing its shape from planar to quasi-spherical as the shock propagates. In Figure 6, we 
also show schematic diagrams of the shadowgraph images at $t=4,12 \mu$ s. The planar detonation wave at $t=4 \mu$ s gradually diffracts from the tube end, and the burned-pressurized gas right behind the detonation wave compresses the ambient air, creating the shock wave. At $t=12 \mu \mathrm{s}$, the shock front seems to be quasi-spherical as expansion waves propagate toward the tube axis and the undisturbed shock front diminishes. Note that the whitish objects at the center of the images in Figure 5 are the ruptured diaphragms.

To compare the continuously transforming shape of the shock fronts, we also show the shadowgraph pile-up images in Figure 7. In Figure 8, we show the shadowgraph images obtained in shot 2, in which $r_{\mathrm{v}}=40-105 \mathrm{~mm}$ as well. Figure 8-(a), (b), (c), (d), (e), (f), (g), and (h) show the shock wave at $t=23$, 27, 31, 35, 39, 43, 47, and $51 \mu$ s, respectively. We show shadowgraph piled-up image of shot 2 in Figure 9. The closest shock front to the open end of the tube was captured at $t=23 \mu \mathrm{s}$, and the shock wave propagates from left to right in Figure 9. In Figure 9, a shock wave was captured every $4 \mu$ s, showing the shape change from quasi-spherical to spherical. From the results obtained, we show an $x-t$ diagram in Figure 10. The data for less than $r=1000 \mathrm{~mm}$ was obtained from the shadowgraph images, and the data for more than $r=1000 \mathrm{~mm}$ was obtained using piezo-pressure sensors. The dot-line in Figure 10 is the approximated first-order line, showing constant speed propagation of a shock wave. We also show the $x$-t diagram in the vicinity from the tube open end and compare the results in detail using two different lengths of tubes in Figure 11.

We confirmed that shock propagation is not highly dependent on the tube length. Using the $x-t$ diagram and Rankin-Hugoniot relation, we calculated peak overpressure of the shock wave in the axial direction, as shown in Figure 12. In Figure 12, the dotted line is the approximated first-order line showing the attenuation characteristic of sound, which generally attenuates in proportion to $1 / r$. Although peak overpressure is initially nearly $p_{\mathrm{CJ}}$ and rapidly decreases toward the dotted line, there seems to be a specific region around $r=0.1 \mathrm{~m}$, in which the gradient of peak overpressure decrease becomes smaller once and becomes larger again. We consider that this is due to the shape transformation of a shock wave from quasi-spherical to completely spherical. When a shock wave is 
quasi-spherical, there should be a pressure gradient on its shock front in which the pressure on the undisturbed shock front is higher than the pressure on the diffracting shock front and the pressure on the diffracting shock front is lower than the pressure on the undisturbed shock front. Hence pressure on the undisturbed shock front should become lower subsequently, and pressure on the diffracting shock front should become higher subsequently.

We show overpressure histories of the shock waves at $r=10,20$, and $30 \mathrm{~m}$ in Figure 13, showing a shock wave followed by an expansion wave and negative pressure region. We also show overpressure histories at $r=98.5,201 \mathrm{~m}$ in Figure 14. Note that pressure histories were shifted to adjust $t=0 \mathrm{~ms}$ so that $t=0 \mathrm{~ms}$ is starting point of pressure rise.

As we mentioned above, one must also estimate the effect of a reflected wave in terms of peak overpressure. Figure 15 shows the pressure history using configurations C1, C2, and C3 in Figure 3, respectively. Figure 15-C1 shows an incident shock combined with a reflected shock. Figure 15-C2 shows an incident shock followed by a pressure wave with approximately 0.5 ms delay. Figure 15-C3 shows an incident shock followed by a pressure wave with approximately 4 ms delay. The delayed wave in Figure 15-C2, C3 is considered to be the reflected wave from the ground surface. From the comparison between Figure 15-C1 and C2, we confirmed that peak overpressure at $r=10 \mathrm{~m}$ can decrease by approximately 58-\% depending on $h_{\mathrm{t}}$ and $h_{\mathrm{p}}$ in our experimental environment. Hence, while any plots in Figures 13, 14, 17, 18, 19 are with no artificial manipulation, we believe that the peak overpressure only by the incident shock at $r=20,30,98.5 \mathrm{~m}$ may be actually lower than the plots in Figure 13, 14, 17, 18, 19.

The obtained results were normalized by the parameters mentioned above, in which the peak overpressure of the generated shock wave was highly dependent on tube diameter. To validate the applicability of the parameters, we carried out experiments with various tube diameters and various tube lengths at $r=10 \mathrm{~m}$ and show the results in Figure 16. We confirmed that the peak overpressure is highly dependent on the tube diameter but not strongly dependent on the tube length. And also, it is observed that the longer tube (Tube B) generates impulse with longer positive phase duration. 
Last, we show the relationship between peak overpressure and the distance from the open end of the tube. Figure 17 shows the decay of peak overpressure and the decreasing of the SPL depending on the distance. In Figure 17, the dotted line and dashed line show the approximated line (proportional to 1/r) fitting into the data using the tube of $D=50 \mathrm{~mm}, L=1200 \mathrm{~mm}$ (Tube A, larger open circle symbol) and $D=27 \mathrm{~mm}, L=1200 \mathrm{~mm}$ (Tube C, smaller open circle symbol), respectively, indicating the sound attenuation characteristic. And also, closed square symbol is the data with $D=50 \mathrm{~mm}$ and $L=6400$ $\mathrm{mm}$. The approximation was conducted using the least-squares method. From the experiments using the tube of $D=27 \mathrm{~mm}$, in the vicinity to the open end of the tube we see that the peak overpressure is nearly equal to C-J pressure, where the shape of the shock front is nearly planar. Subsequently, peak overpressure begins to decrease rapidly toward the approximated line. In the range from approximately $r=0.1 \mathrm{~m}$ to $r=0.3 \mathrm{~m}$, where the shape of the shock front transforms from quasi-spherical to complete spherical. In the range from approximately $r=10 \mathrm{~m}$ up to $r=30 \mathrm{~m}$, the peak overpressure decays approximately with the sound attenuation characteristic indicated by the dotted line. From the experiments using the tube of $D=50 \mathrm{~mm}$, in approximately $r \geq 10 \mathrm{~m}$ we see that the peak overpressure seems to decay more rapidly than the ideal sound attenuation indicated by the dashed line. This may have been due to viscous effect. In addition, we also show the previous results obtained by Sochet et al. [24] with various tube diameters and mixtures, as shown in Figure 17.

We normalized our results using two non-dimensional parameters [24], as shown in Figure 18. The results with various tube diameters seem to lie on one curve. Our results and their results seem to be in good agreement. In approximately $R_{d} \leq 0.4$, the shock wave is nearly planar and does not significantly attenuate and peak overpressure maintains approximately C-J pressure. In approximately $R_{d} \approx 0.4-10$, while the shock wave is initially quasi-spherical and eventually becomes spherical, the shock wave attenuates rapidly and peak overpressure decreases toward approximately $\mathrm{P} \cong 0.1$. In approximately $\mathrm{R}_{\mathrm{d}} \approx 10-60$, the shock wave propagates with approximately the sound characteristic so that peak 
overpressure decreases in proportion to $1 / r$. In approximately $R_{d} \geq 60$, the shock wave begins to attenuate more rapidly than ideal sound attenuation.

As mentioned above, we also compared our results with the results [21, 22] using the open-ended shock tube with the non-dimensional parameters proposed by Schmidt et al. [21] in Figure 19. Their results are approximately three times as great as our results under normalized pressure. This may be mainly due to the difference of pressure profile within a tube either when a detonation wave reaches the open end or when high-pressure gas accumulated within a shock tube begins to expand through the open end. While the pressure profile right behind a shock front within a shock tube is approximately constant, the pressure profile right behind a detonation wave is not constant but decreases rapidly in the opposite direction from shock propagation. Due to the difference of pressure profile, it is not possible to simply apply these non-dimensional parameters to detonation-drive shock waves. 


\section{Conclusion}

Peak overpressure and the shape transition of the shock waves emerging from the tube open end were observed depending on the distance from the tube open end using shadowgraph optical visualization and pressure sensors. Firstly, we confirmed data consistency with Sochet et al. [24]. Secondly, we addressed the peak overpressure decay with better spatial resolution using visualization and much broader distance from the tube open end than Sochet et al. [24] and shape transition of the shock wave. The results obtained in the present study were normalized using non-dimensional distance $\mathrm{R}_{\mathrm{d}}$ and non-dimensional pressure P. In approximately $R_{d} \leq 0.4$, the shock wave is nearly planar and does not significantly attenuate and peak overpressure maintains approximately C-J pressure. In approximately $R_{d} \approx 0.4-10$, while the shock wave is initially quasi-spherical and eventually becomes spherical, the shock wave attenuates rapidly and peak overpressure decreases toward approximately $\mathrm{P} \cong 0.1$. In approximately $\mathrm{R}_{\mathrm{d}} \approx 10-60$, the shock wave propagates with approximately the sound characteristic so that peak overpressure decreases in proportion to $1 / r$. In approximately $R_{d} \geq 60$, the shock wave begins to attenuate more rapidly than ideal sound attenuation. As the propagation distance from the tube open end increases, the difference between the peak overpressure obtained and the ideal sound attenuation increases, which may be due to the viscous effect.

\section{Acknowledgements}

The shadowgraph optical visualization was supported by H. Kusano from Shimadzu Co., Ltd. The experimental setup was constructed by A. Kojima from the University of Tsukuba. This work was subsidized by the Ministry of Education, Culture, Sports, Science, and Technology via a Grant-In-Aid for Scientific Research (A), No. 20241040 and a Grant-In-Aid for Scientific Research (B), No. 2360411. 


\section{References}

[1] K. Kailasanath, (2000) Review of Propulsion Applications of Detonation Waves. AIAA Journal, Vol. 38, No. 9: 1698-1708

[2] K. Kailasanath, (2003) Recent Developments in the Research on Pulse Detonation Engines. AIAA Journal, Vol. 41, No. 2: 145-159

[3] T. V. Bazhenova, V. V. Golub, (2003) Use of Gas Detonation in a Controlled Frequency Mode (Review). Combustion, Explosion, and Shock Waves, Vol. 39, No. 4: 365-381

[4] G. D. Roy, S. M. Frolov, A. A. Borisov, D. W. Netzer, (2004) Pulse Detonation Propulsion: Challenges, Current Status, and Future Perspective. Progress in Energy and Combustion Science, Vol. 30, No. 6: 545-672

[5] J. Kasahara, A. Hasegawa, T. Nemoto, H. Yamaguchi, T. Yajima, T. Kojima, (2009) Performance Validation of a Single-Tube Pulse Detonation Rocket System. Journal of Propulsion and Power, Vol. 25, No. 1: 173-180

[6] T. Endo, T. Fujiwara, (2002) A Simplified Analysis on a Pulse Detonation Engine Model. Transactions of the Japan Society for Aeronautical and Space Sciences. Vol. 44, Issue 146: 217222

[7] T. Endo, J. Kasahara, A. Matsuo, K. Inaba, S. Sato, T. Fujiwara, (2004) Pressure History at the Thrust Wall of a Simplified Pulse Detonation Engine. AIAA Journal. Vol. 42, No. 9: 1921-1929

[8] T. Endo, T. Yatsufusa, S. Taki, A. Matsuo, K. Inaba, J. Kasahara, (2007) Homogeneous-Dilution Model of Partially-Fueled Simplified Pulse Detonation Engines. Journal of Propulsion and Power. Vol. 23, No. 5: 1033-1041

[9] J. Kasahara, M. Hirano, A. Matsuo, Y. Daimon, T. Endo, (2008) Thrust Measurement of a MultiCycle Partially Filled Pulse Detonation Rocket Engine. Journal of Propulsion and Power

[10] J. Kasahara, Z. Liang, S. T. Browne, J. E. Shepherd, (2008) Impulse Generation by an Open Shock Tube. AIAA Journal. Vol. 46, No. 7: 1593-1603

[11] J. Brossard, P. Bailly, C. Desrosier, J. Renard, (1988) Overpressures Imposed by a Blast Wave. Progress in Astronautics and Aeronautics. AIAA: 389-400

[12] J. Brossard, S. Hendrickx, J. L. Garnier, A. Lannoy, J. L. Perrot, (1984) Air Blast from Unconfined Gaseous Detonations. Proceedings of the 9th International Colloquium on Dynamics of Explosions and Reactive Systems, the American Institute of Aeronautics and Astronautics: 556-566 
[13] J. Brossard, I. Sochet, (2000) Direct Initiation of Gaseous Detonation: the Jungle. Journal de Physique 4. Vol. 10, No. PR11: 81-89

[14] S. Sénégas, C. Vaglio, J. Brossard, R. Cayzac, (2000) Quasi Universal Blast Wave Behavior. Journal de Physique 4. Vol. 10, No. PR11: 91-98

[15] M. J. Tang, Q. A. Baker, (1999) A New Set of Blast Curves from Vapor Cloud Explosion. Process Safety Progress. Vol. 18, Issue 4: 235-240

[16] M. J. Tang, Q. A. Baker, (2000) Comparison of Blast Curves from Vapor Cloud Explosions. Journal of Loss Prevention in the Process Industries. Vol. 13, Issues 3-5: 433-438

[17] M. M. Ismail, S. G. Murray, (1993) Study of the Blast Wave Parameters from Small Scale Explosions. Propellants, Explosives, Pyrotechnics. Vol. 18, Issue 1: 11-17

[18] M. M. Ismail, S. G. Murray, (1993) Study of the Blast Waves from the Explosion of Nonspherical Charges. Propellants, Explosives, Pyrotechnics. Vol. 18, Issue 3. 132-138

[19] M. Held, (1983) Blast Waves in Free Air. Propellants, Explosives, Pyrotechnics. Vol. 8, Issue 1: 17

[20] K. S. Fansler, E. M. Schmidt, (1982) The Relationship Between Interior Ballistics, Gun Exhaust Parameters and the Muzzle Blast Overpressure. AIAA/ASME 3rd Joint Thermophysics, Fluid, Plasma and Heat transfer Conference (AIAA-82-0856)

[21] E. M. Schmidt, S. J. Duffy, (1985) Noise from Shock Tube Facilities. AIAA 23rd Aerospace Sciences Meeting (AIAA-85-0049)

[22] Brian P. Bertrand, William T. Matthews, (1965) Overpressures and Durations of Shock Waves Emerging from Open-ended Shock Tubes. Memorandum report. No. 1724

[23] I. Sochet, J. Brossard, (1997) Critical Radius of Explosive Gaseous Mixtures with Initial Concentration Gradients. Shock Waves. Vol. 7, No. 1: 29-32

[24] I. Sochet, T. Lamy, J. Brossard, (1999) Critical Tube Diameter for Detonation Transmission and Critical Initiation Energy of Spherical Detonation. Shock Waves. Vol. 9, No. 2: 113-123

[25] I. Sochet, T. Lamy, J. Brossard, (2000) Experimental Investigation on the Detonability of Nonuniform Gaseous Mixtures. Shock Waves. Vol.10, No. 5: 363-376

[26] C. Vaglio, R. Cayzac, J. Brossard, (1997) Shock Wave Characteristics at the Open End of a Detonation Tube. Proceeding of the 6th International Colloquium on the Dynamics of Explosions and Reactive Systems: 95-98 
[27] D. Allgood, E. Gutmark, T. Meyer, J. Hoke, V. Katta, F. Schauer, J. R. Gord, (2003) Computational and Experimental Studies of Pulse Detonation Engines. 41st AIAA Aerospace Sciences Meeting and Exhibit

[28] A. Glaser, D. Allgood, E. Gutmark, (2004) Experimental Investigation into the Off-Design Performance of a Pulse Detonation Engine. 42nd AIAA Aerospace Science Meeting and Exhibit

[29] S. Kato, S. Hashimoto, A. Uemichi, J. Kasahara, A. Matsuo, (2009) Study on Propagation Characteristics of the Shock Waves Driven by Gaseous Detonation Waves. Proceeding of the 22nd International Colloquium on the Dynamics of Explosions and Reactive Systems

[30] K. Tanaka, Thermochemical Database of Gases and Condensed Materials: AISTJAN. http://riodb.ibase.aist.go.jp/ChemTherm/index-E.html. Accessed 11 August 2009 
Table 1 Experimental conditions (shadowgraph optical visualization)

\begin{tabular}{ccccccccccccc}
\hline $\begin{array}{c}\text { Shot } \\
\text { number }\end{array}$ & $\begin{array}{c}\text { Detonable } \\
\text { mixture }\end{array}$ & $p_{0}$ & $D$ & $L$ & $\begin{array}{c}\text { Tube } \\
\text { type }\end{array}$ & $\delta$ & $r_{\mathrm{v}}$ & $T_{\text {atm }}$ & $p_{\text {atm }}$ & $T_{\mathrm{CJ}}$ & $p_{\mathrm{CJ}}$ & $u_{\mathrm{CJ}}$ \\
& & $\mathrm{kPa}$ & $\mathrm{mm}$ & $\mathrm{mm}$ & - & $\mu \mathrm{m}$ & $\mathrm{mm}$ & $\mathrm{K}$ & $\mathrm{kPa}$ & $\mathrm{K}$ & $\mathrm{kPa}$ & $\mathrm{m} / \mathrm{s}$ \\
\hline 1 & $\mathrm{C}_{2} \mathrm{H}_{4}+3 \mathrm{O}_{2}$ & 101.6 & 27 & 1200 & $\mathrm{C}$ & 12 & $15-48$ & 293.5 & 101.6 & 3941 & 3459 & 1110 \\
2 & $\mathrm{C}_{2} \mathrm{H}_{4}+3 \mathrm{O}_{2}$ & 100.5 & 27 & 1200 & $\mathrm{C}$ & 1.5 & $38-99$ & 299.0 & 100.5 & 3938 & 3356 & 1110 \\
3 & $\mathrm{C}_{2} \mathrm{H}_{4}+3 \mathrm{O}_{2}$ & 100.9 & 27 & 1200 & $\mathrm{C}$ & 1.5 & $84-142$ & 297.0 & 100.9 & 3939 & 3393 & 1110 \\
4 & $\mathrm{C}_{2} \mathrm{H}_{4}+3 \mathrm{O}_{2}$ & 100.9 & 27 & 1200 & $\mathrm{C}$ & 1.5 & $114-168$ & 297.5 & 100.9 & 3939 & 3387 & 1110 \\
5 & $\mathrm{C}_{2} \mathrm{H}_{4}+3 \mathrm{O}_{2}$ & 100.9 & 27 & 1200 & $\mathrm{C}$ & 1.5 & $115-166$ & 297.5 & 100.9 & 3939 & 3387 & 1110 \\
6 & $\mathrm{C}_{2} \mathrm{H}_{4}+3 \mathrm{O}_{2}$ & 100.9 & 27 & 1200 & $\mathrm{C}$ & 1.5 & $150-194$ & 297.5 & 100.9 & 3939 & 3387 & 1110 \\
7 & $\mathrm{C}_{2} \mathrm{H}_{4}+3 \mathrm{O}_{2}$ & 100.9 & 27 & 1200 & $\mathrm{C}$ & 1.5 & $260-323$ & 297.5 & 100.9 & 3939 & 3387 & 1110 \\
8 & $\mathrm{C}_{2} \mathrm{H}_{4}+3 \mathrm{O}_{2}$ & 100.9 & 27 & 1200 & $\mathrm{C}$ & 1.5 & $537-575$ & 297.5 & 100.9 & 3939 & 3387 & 1110 \\
9 & $\mathrm{C}_{2} \mathrm{H}_{4}+3 \mathrm{O}_{2}$ & 101.0 & 27 & 6400 & $\mathrm{D}$ & 1.5 & $37-93$ & 301.2 & 101.0 & 3936 & 3348 & 1110 \\
10 & $\mathrm{C}_{2} \mathrm{H}_{4}+3 \mathrm{O}_{2}$ & 101.0 & 27 & 6400 & $\mathrm{D}$ & 1.5 & $85-144$ & 301.2 & 101.0 & 3936 & 3348 & 1110 \\
11 & $\mathrm{C}_{2} \mathrm{H}_{4}+3_{2} \mathrm{O}_{2}$ & 101.0 & 27 & 6400 & $\mathrm{D}$ & 1.5 & $135-197$ & 301.2 & 101.0 & 3936 & 3348 & 1110 \\
\hline
\end{tabular}


Table 2 Experimental conditions (overpressure measurement)

\begin{tabular}{|c|c|c|c|c|c|c|c|c|c|c|c|c|c|c|c|}
\hline $\begin{array}{c}\text { Shot } \\
\text { number }\end{array}$ & $\begin{array}{l}\text { Detonable } \\
\text { mixture }\end{array}$ & $\begin{array}{r}p_{0} \\
\mathrm{kPa}\end{array}$ & $\begin{array}{c}D \\
\mathrm{~mm}\end{array}$ & $\begin{array}{c}L \\
\mathrm{~mm}\end{array}$ & $\begin{array}{l}\text { Tube } \\
\text { type } \\
-\end{array}$ & $\begin{array}{c}\delta \\
\mu \mathrm{m}\end{array}$ & $\begin{array}{l}r \\
\mathrm{~m}\end{array}$ & $\begin{array}{l}h_{\mathrm{t}} \\
\mathrm{m}\end{array}$ & $\begin{array}{l}h_{\mathrm{p}} \\
\mathrm{m}\end{array}$ & Config. & $\begin{array}{c}T_{\mathrm{atm}} \\
\mathrm{K}\end{array}$ & $\begin{array}{l}p_{\text {atm }} \\
\mathrm{kPa}\end{array}$ & $\begin{array}{c}T_{\mathrm{CJ}} \\
\mathrm{K}\end{array}$ & $\begin{array}{l}p_{\mathrm{CJ}} \\
\mathrm{kPa}\end{array}$ & $\begin{array}{l}u_{\mathrm{CJ}} \\
\mathrm{m} / \mathrm{s}\end{array}$ \\
\hline 12 & $\mathrm{C}_{2} \mathrm{H}_{4}+3 \mathrm{O}_{2}$ & 100.5 & 50 & 1200 & A & 12 & 1.0 & 0.5 & 0.5 & $\mathrm{C} 1$ & 299.0 & 100.5 & 3938 & 3356 & 1110 \\
\hline 13 & $\mathrm{C}_{2} \mathrm{H}_{4}+3 \mathrm{O}_{2}$ & 101.7 & 50 & 1200 & A & 12 & 10.0 & 0.5 & 0.5 & $\mathrm{C} 1$ & 288.0 & 101.7 & 3945 & 3531 & 1111 \\
\hline 14 & $\mathrm{C}_{2} \mathrm{H}_{4}+3 \mathrm{O}_{2}$ & 103.0 & 50 & 1200 & A & 12 & 20.0 & 0.5 & 0.5 & $\mathrm{C} 1$ & 286.0 & 103.0 & 3946 & 3602 & 1111 \\
\hline 15 & $\mathrm{C}_{2} \mathrm{H}_{4}+3 \mathrm{O}_{2}$ & 101.7 & 50 & 1200 & A & 12 & 30.0 & 0.5 & 0.5 & C1 & 292.5 & 101.7 & 3942 & 3475 & 1110 \\
\hline 16 & $\mathrm{C}_{2} \mathrm{H}_{4}+3 \mathrm{O}_{2}$ & 102.2 & 50 & 1200 & A & 12 & 98.5 & 1.0 & 1.0 & C2 & 281.5 & 102.2 & 3949 & 3633 & 1111 \\
\hline 17 & $\mathrm{C}_{2} \mathrm{H}_{4}+3 \mathrm{O}_{2}$ & 292.5 & 50 & 1200 & A & 12 & 201 & 0.5 & 47.0 & C3 & 292.5 & 101.8 & 3942 & 3478 & 1110 \\
\hline 18 & $\mathrm{C}_{2} \mathrm{H}_{4}+3 \mathrm{O}_{2}$ & 101.2 & 50 & 1200 & A & 12 & 10.0 & 1.0 & 1.0 & C2 & 282.0 & 101.2 & 3949 & 3591 & 1111 \\
\hline 19 & $\mathrm{C}_{2} \mathrm{H}_{4}+3 \mathrm{O}_{2}$ & 101.2 & 50 & 1200 & A & 12 & 10.0 & 1.0 & 7.0 & C3 & 282.0 & 101.2 & 3949 & 3591 & 1111 \\
\hline 20 & $\mathrm{C}_{2} \mathrm{H}_{4}+3 \mathrm{O}_{2}$ & 101.5 & 50 & 2400 & B & 12 & 10.0 & 1.0 & 1.0 & C2 & 283.0 & 101.5 & 3984 & 3588 & 1111 \\
\hline 21 & $\mathrm{C}_{2} \mathrm{H}_{4}+3 \mathrm{O}_{2}$ & 101.5 & 27 & 1200 & C & 12 & 10.0 & 1.0 & 1.0 & C2 & 283.0 & 101.5 & 3984 & 3588 & 1111 \\
\hline
\end{tabular}


Table 3 The tube exit conditions, energy supplied to outside volume, and scaling lengths

\begin{tabular}{ccccccccccccc}
\hline $\begin{array}{c}\text { Detonable } \\
\text { mixture }\end{array}$ & $R$ & $p_{\mathrm{CJ}}$ & $T_{\mathrm{CJ}}$ & $\rho_{\mathrm{CJ}}$ & $\gamma_{\mathrm{CJ}}$ & $u_{\mathrm{CJ}}$ & $C_{\mathrm{vCJ}}$ & $D$ & $E_{0}$ & $W_{\mathrm{d}}$ & $\dot{E}$ & $W_{\mathrm{s}}$ \\
& $\mathrm{J} /(\mathrm{kg} \mathrm{K})$ & $\mathrm{kPa}$ & $\mathrm{K}$ & $\mathrm{m} / \mathrm{s}^{3}$ & - & $\mathrm{m} / \mathrm{s}$ & $\mathrm{J} /(\mathrm{kg} \mathrm{K})$ & $\mathrm{mm}$ & $\mathrm{J}$ & $\mathrm{m}$ & $\mathrm{J} / \mathrm{s}$ & $\mathrm{m}$ \\
\hline $\mathrm{C}_{2} \mathrm{H}_{4}+3 \mathrm{O}_{2}$ & 268.0 & 3459 & 3941 & 3.3 & 1.239 & 1110 & 1122 & 27 & 53.0 & 0.081 & 9.180 & 0.514 \\
$\mathrm{C}_{2} \mathrm{H}_{4}+3_{2}$ & 268.0 & 3459 & 3941 & 3.3 & 1.239 & 1110 & 1122 & 50 & 336.5 & 0.149 & 36.718 & 1.028 \\
$\mathrm{H}_{2}+0.5 \mathrm{O}_{2}$ & 692.3 & 1986 & 3689 & 0.8 & 1.218 & 1334 & 3176 & 16 & 6.3 & 0.040 & 2.629 & 0.275 \\
$\mathrm{C}_{3} \mathrm{H}_{8}+3 \mathrm{O}_{2}$ & 237.4 & 4677 & 3781 & 5.2 & 1.238 & 1202 & 998 & 16 & 14.5 & 0.052 & 5.663 & 0.404 \\
$\mathrm{C}_{3} \mathrm{H}_{8}+3_{2}$ & 237.4 & 4677 & 3781 & 5.2 & 1.238 & 1202 & 998 & 26 & 62.1 & 0.085 & 14.955 & 0.656 \\
$\mathrm{C}_{3} \mathrm{H}_{8}+3 \mathrm{O}_{2}$ & 237.4 & 4677 & 3781 & 5.2 & 1.238 & 1202 & 998 & 36 & 164.9 & 0.118 & 28.670 & 0.908 \\
$\mathrm{C}_{3} \mathrm{H}_{8}+5 \mathrm{O}_{2}$ & 244.4 & 3828 & 3838 & 4.1 & 1.226 & 1107 & 1081 & 16 & 14.4 & 0.052 & 4.320 & 0.353 \\
$\mathrm{C}_{3} \mathrm{H}_{8}+5 \mathrm{O}_{2}$ & 244.4 & 3828 & 3838 & 4.1 & 1.226 & 1107 & 1081 & 26 & 61.6 & 0.085 & 11.408 & 0.573 \\
$\mathrm{C}_{3} \mathrm{H}_{8}+5 \mathrm{O}_{2}$ & 244.4 & 3828 & 3838 & 4.1 & 1.226 & 1107 & 1081 & 36 & 163.6 & 0.117 & 21.872 & 0.793 \\
$\mathrm{C}_{3} \mathrm{H}_{8}+7 \mathrm{O}_{2}$ & 248.1 & 3330 & 3711 & 3.6 & 1.223 & 1046 & 1111 & 16 & 10.3 & 0.047 & 3.551 & 0.320 \\
$\mathrm{C}_{3} \mathrm{H}_{8}+7_{2}$ & 248.1 & 3330 & 3711 & 3.6 & 1.223 & 1046 & 1111 & 26 & 45.8 & 0.077 & 9.376 & 0.520 \\
$\mathrm{C}_{3} \mathrm{H}_{8}+7_{2}$ & 2481 & 3330 & 3711 & 3.6 & 1.223 & 1046 & 1111 & 36 & 125.3 & 0.107 & 17.976 & 0.719 \\
\hline
\end{tabular}




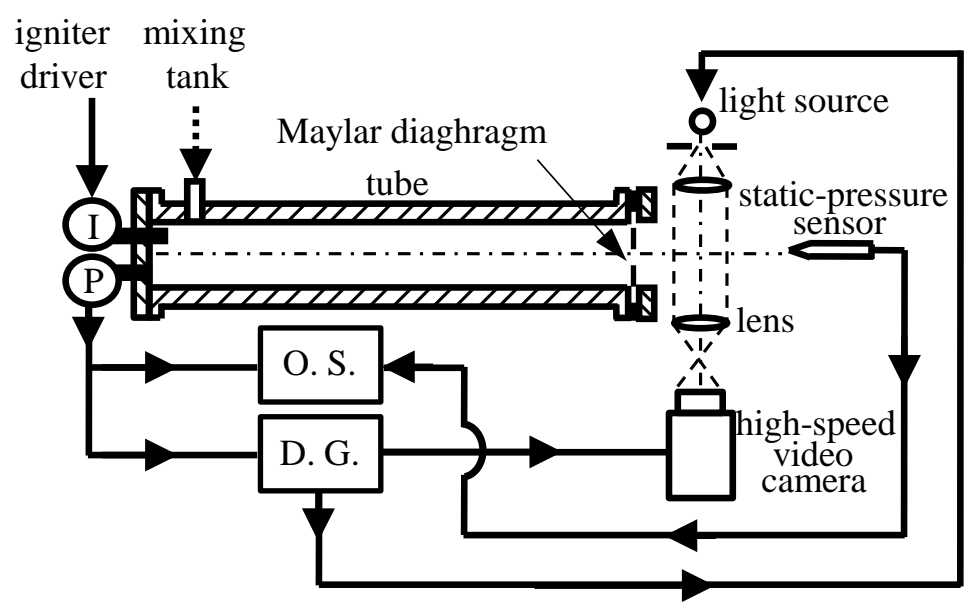

Fig. 1 Shadowgraph optical visualization and overpressure measurement (I: igniter, P: piezo-pressure sensor, O.S.: oscilloscope, D.G.: delay generator) 

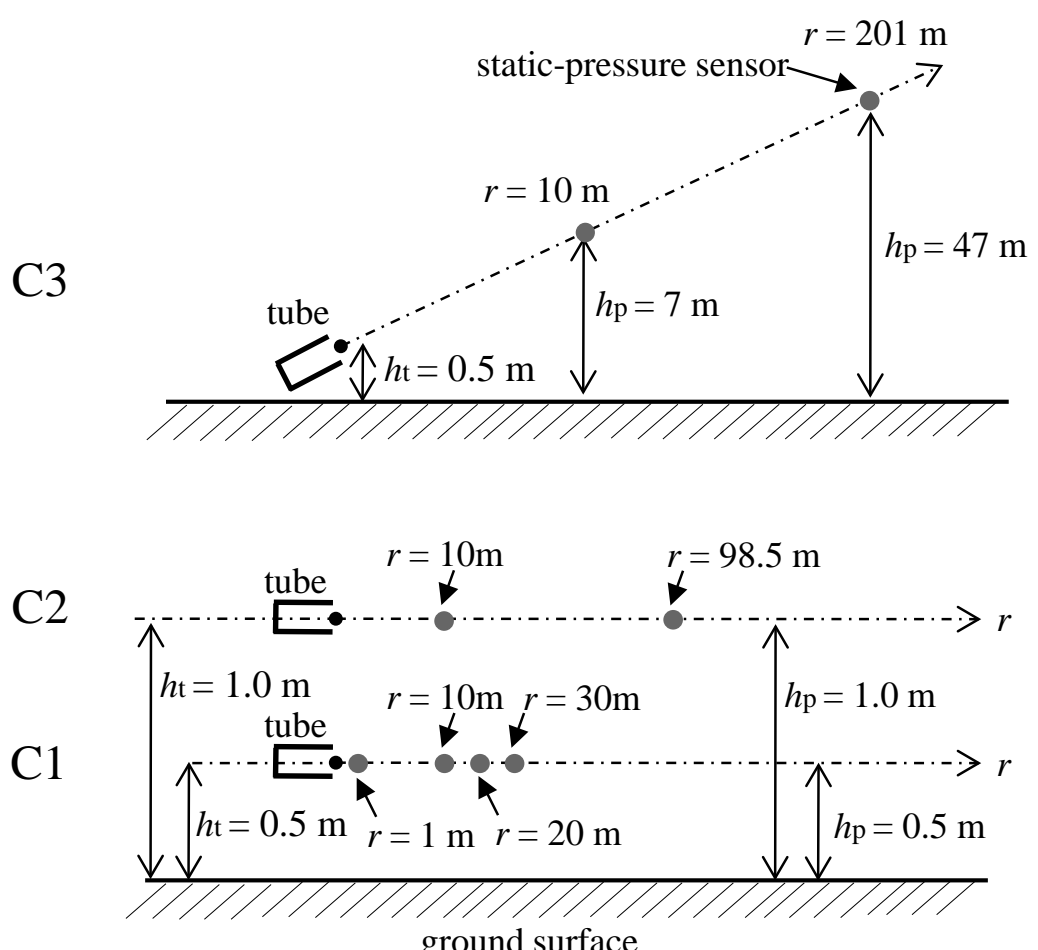

ground surface

Fig. 2 Experimental configuration and location of the pressure sensor ( $r[\mathrm{~m}]$ : the distance between the tube open end and the pressure sensor) 


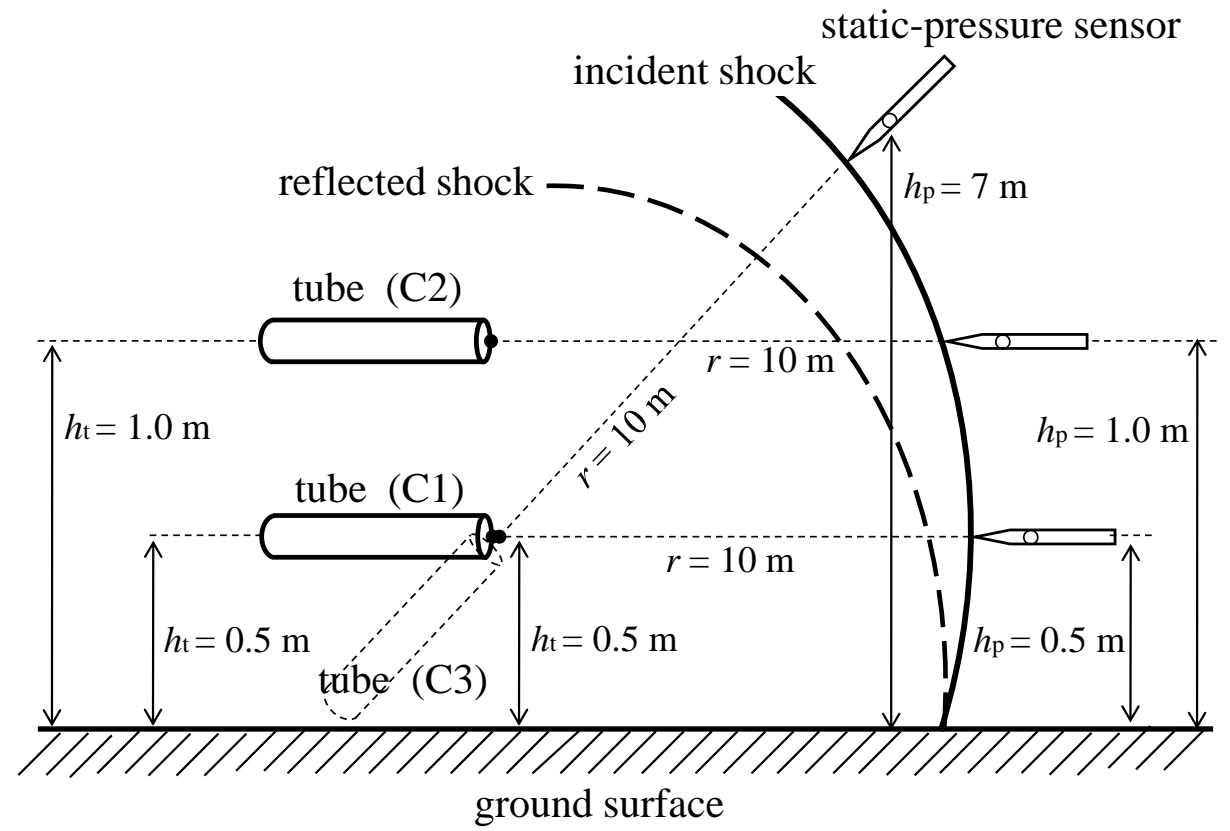

Fig. 3 The experiments at $r=10 \mathrm{~m}$ with various configurations of the tube and pressure sensor 


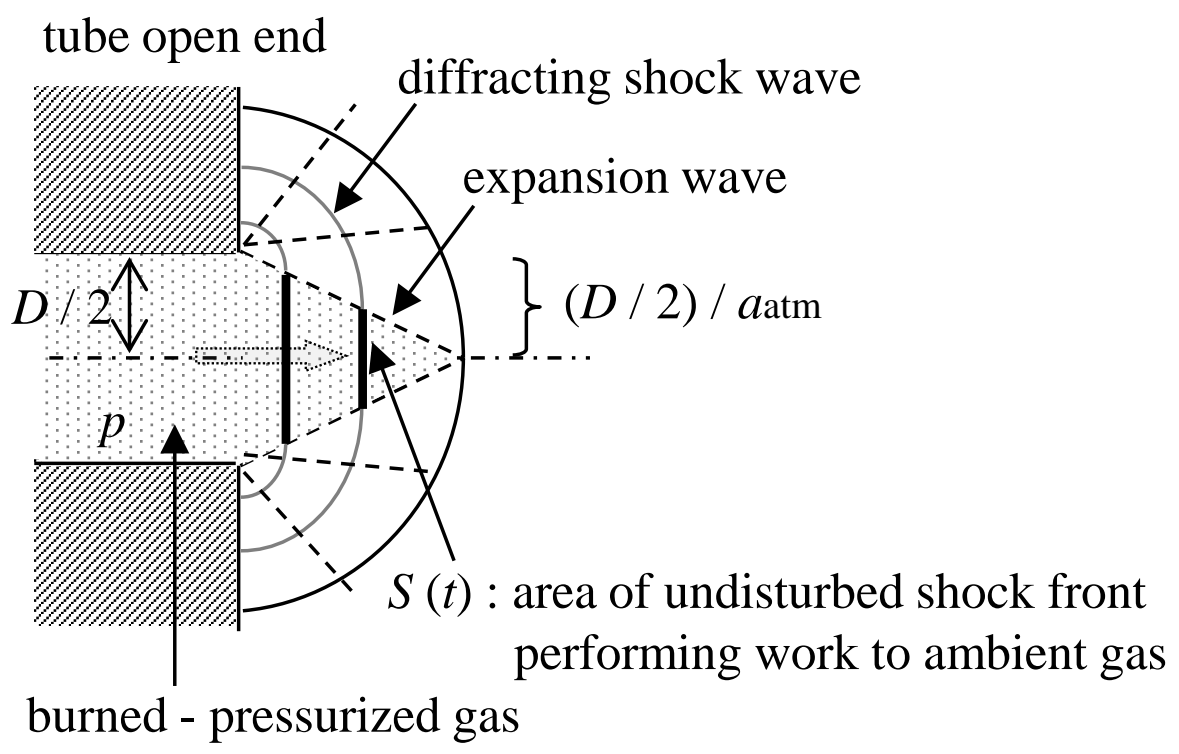

Fig. 4 Schematic diagram of a shock wave performing work against ambient gas ( $D[\mathrm{~mm}]$ : tube diameter) 


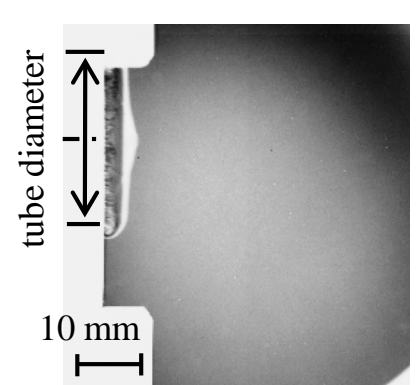

(a) $t=4 \mu \mathrm{s}$

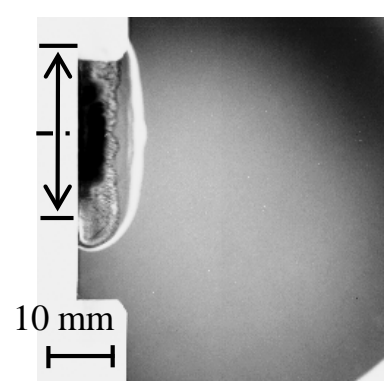

(b) $t=8 \mu \mathrm{s}$

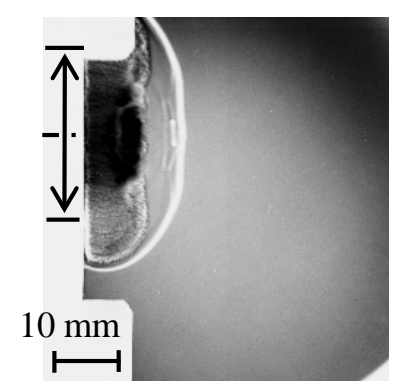

(c) $t=12 \mu \mathrm{s}$

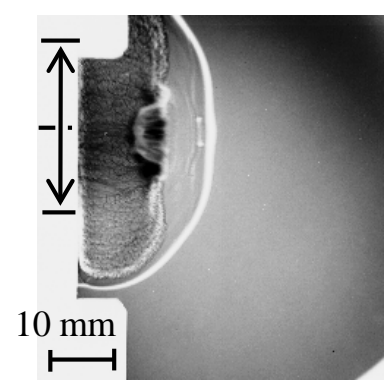

(d) $t=16 \mu \mathrm{s}$

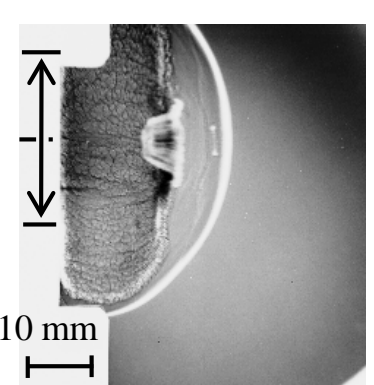

(e) $t=20 \mu \mathrm{s}$

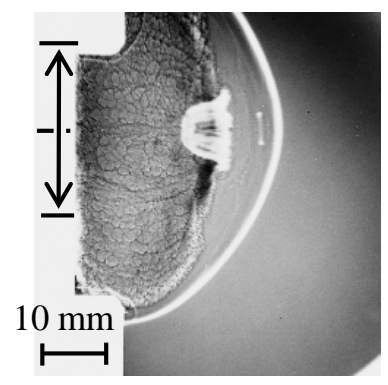

(f) $t=24 \mu \mathrm{s}$

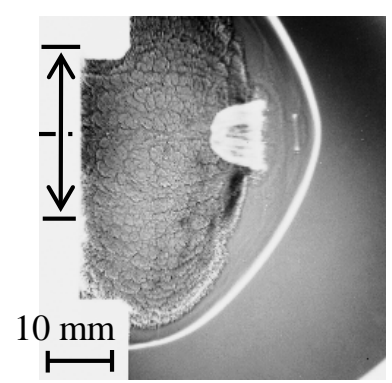

(g) $t=28 \mu \mathrm{s}$

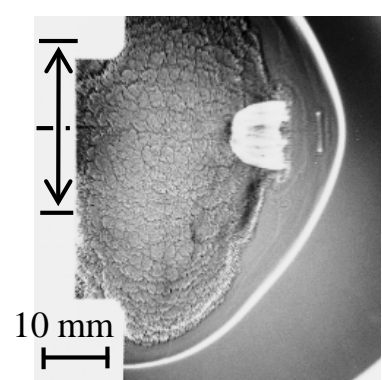

(h) $t=32 \mu \mathrm{s}$

Fig. 5 Color reversal shadowgraph images (Shot 1 , $r=15-70 \mathrm{~mm}, t=4-32 \mu \mathrm{s}, t=0$ : rupture of a diaphragm, Tube C) 

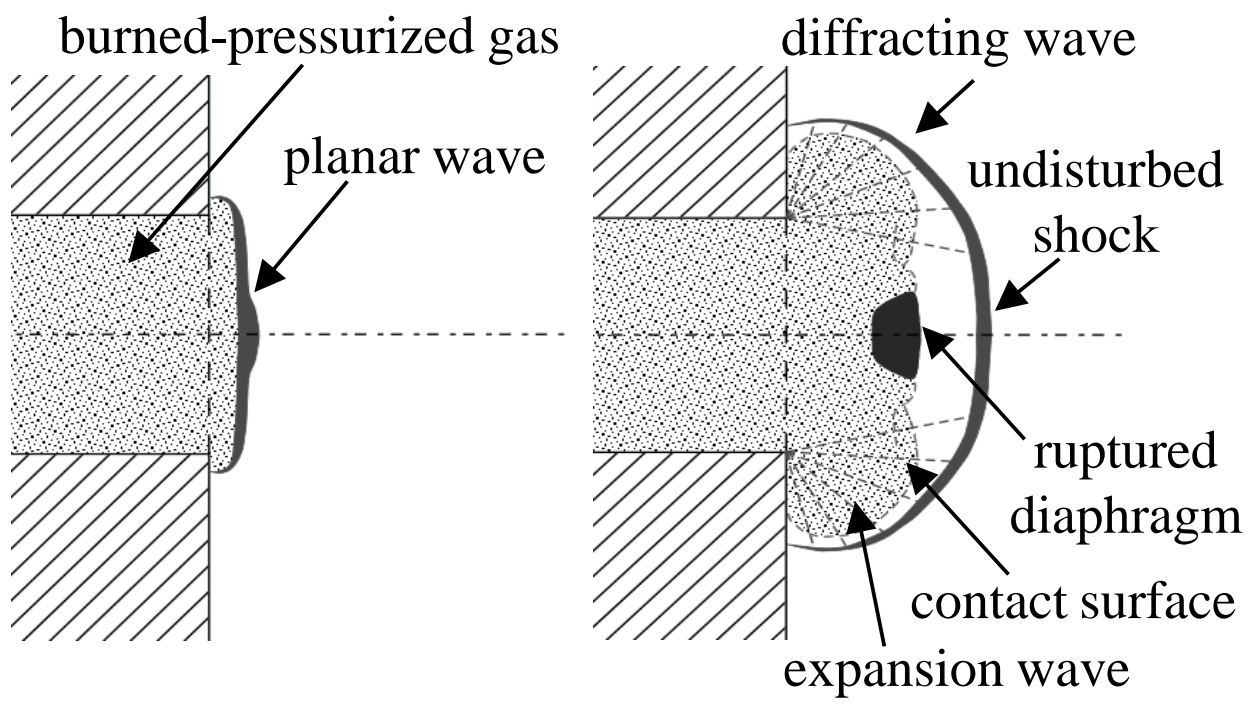

Fig. 6 Schematic diagram of the shock wave near the tube open end (Shot 1, left: $t=4 \mu \mathrm{s}$, right: $t=12 \mu \mathrm{s}, t=0$ : rupture of a diaphragm, Tube C) 


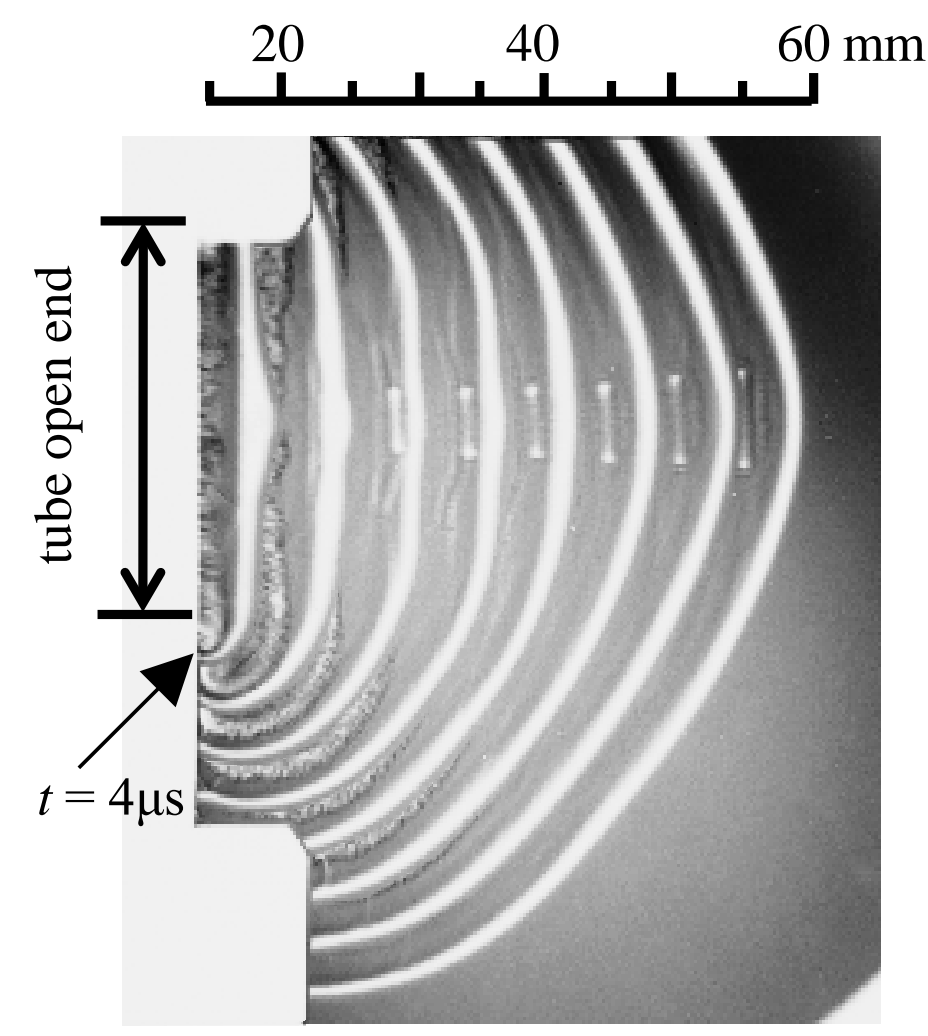

Fig. 7 Shadowgraph piled-up image (Shot 1, $r=15-60 \mathrm{~mm}$, interframe time $=4 \mu \mathrm{s}, t=0$ : rupture of a diaphragm, Tube C) 


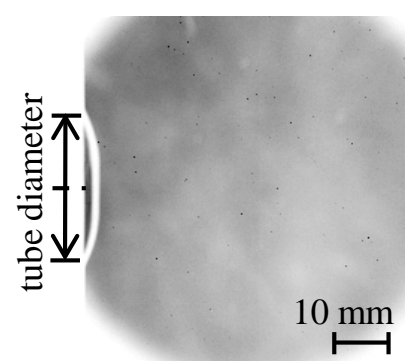

(a) $t=23 \mu \mathrm{s}$

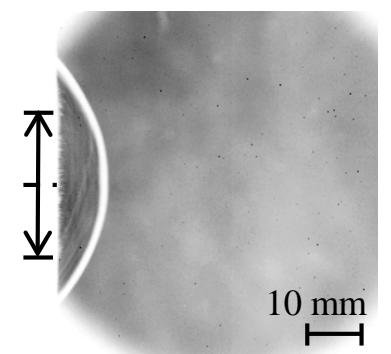

(b) $t=27 \mu \mathrm{s}$

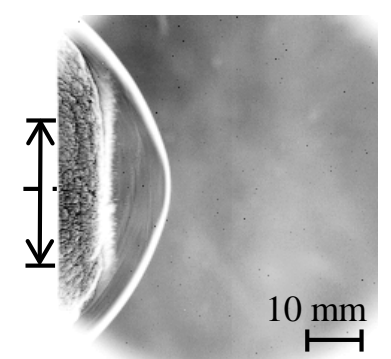

(c) $t=31 \mu \mathrm{s}$

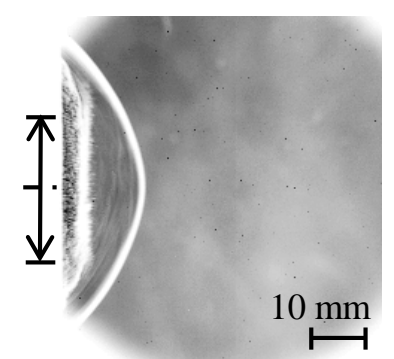

(d) $t=35 \mu \mathrm{s}$

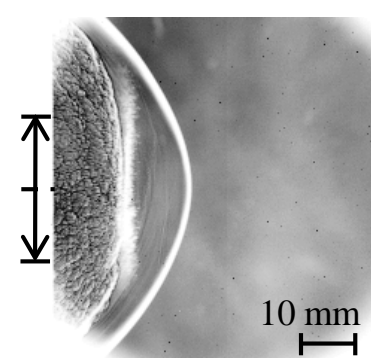

(e) $t=39 \mu \mathrm{s}$

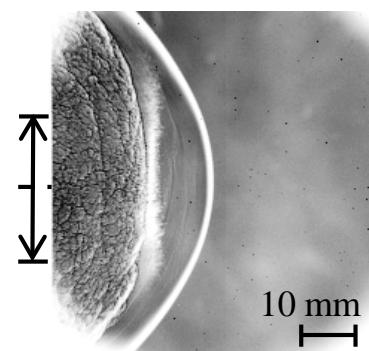

(f) $t=43 \mu \mathrm{s}$

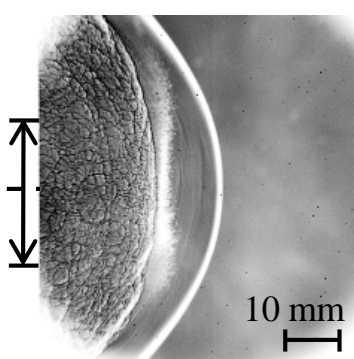

(g) $t=47 \mu \mathrm{s}$

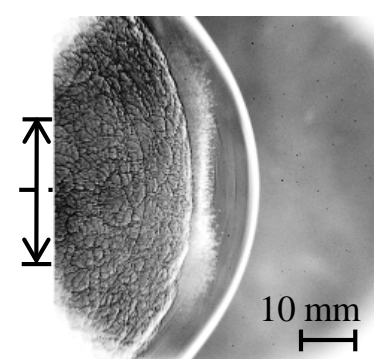

(h) $t=51 \mu \mathrm{s}$

Fig. 8 Color reversal shadowgraph images (Shot 2, $r=40-80 \mathrm{~mm}, t=23-51 \mu \mathrm{s}, t=0$ : rupture of a diaphragm, Tube C) 


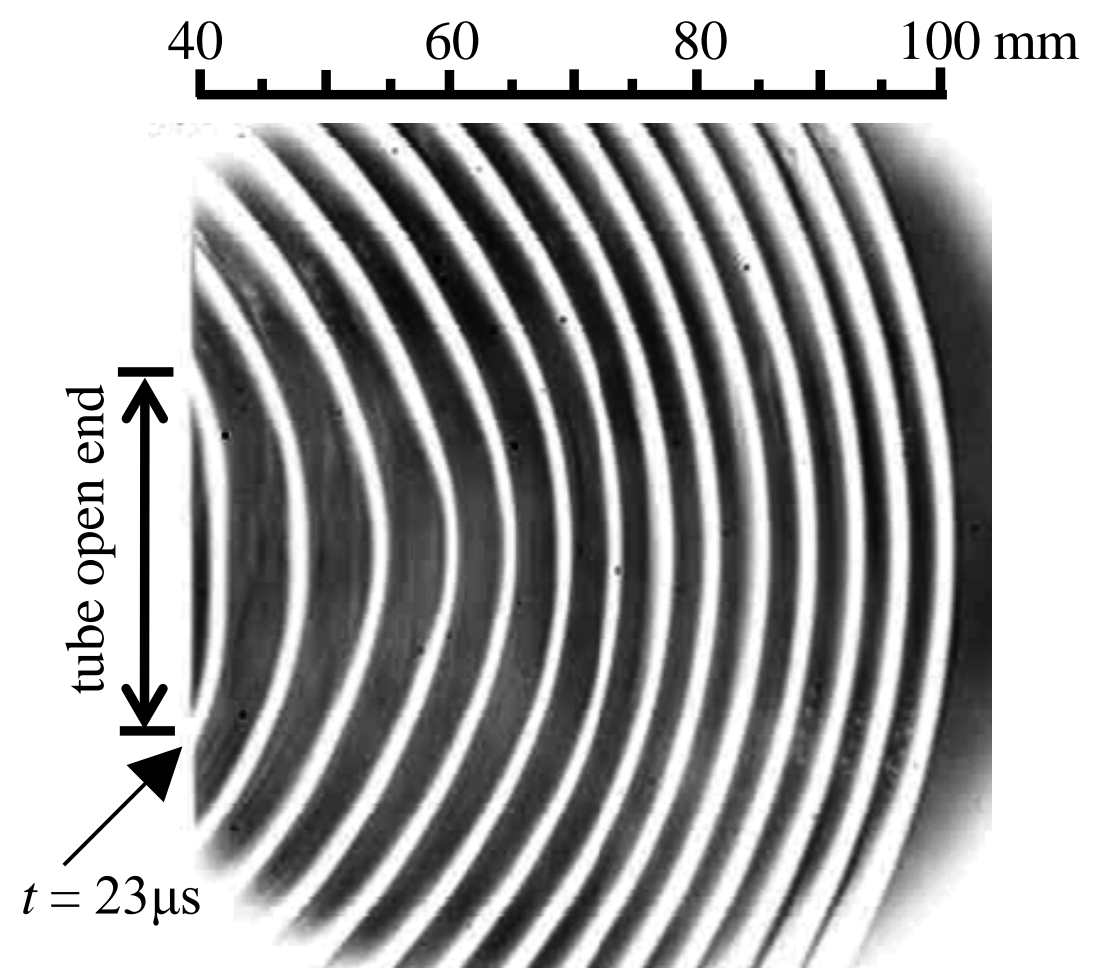

Fig. 9 Shadowgraph piled-up image (Shot 2, $r=40-105 \mathrm{~mm}$, interframe time $=4 \mu \mathrm{s}, t=0$ : rupture of a diaphragm, Tube C) 


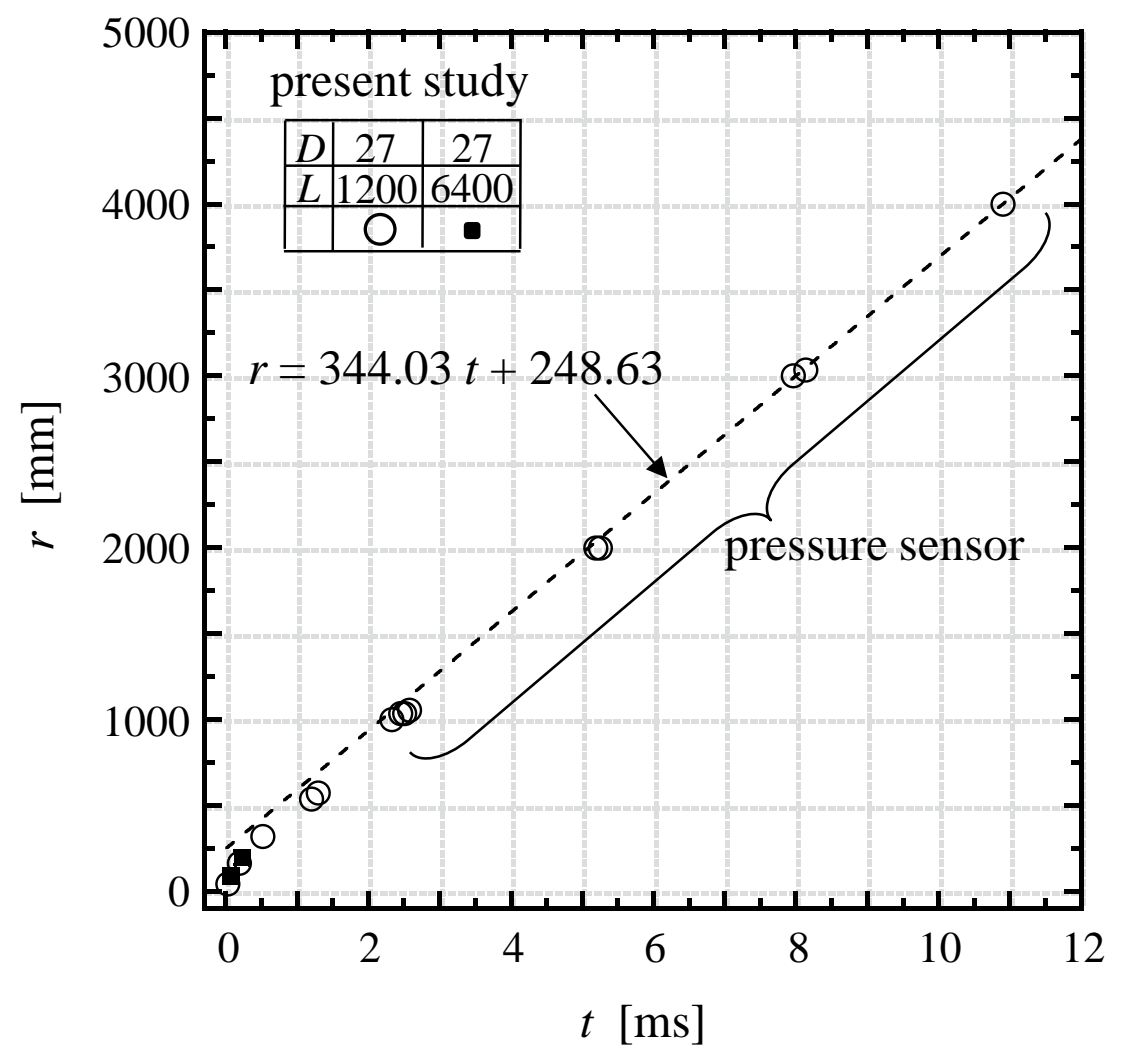

Fig. $10 r$ - $t$ diagram (near the tube open end)

( $D[\mathrm{~mm}]$ : tube diameter, $L[\mathrm{~mm}]$ : tube length) 


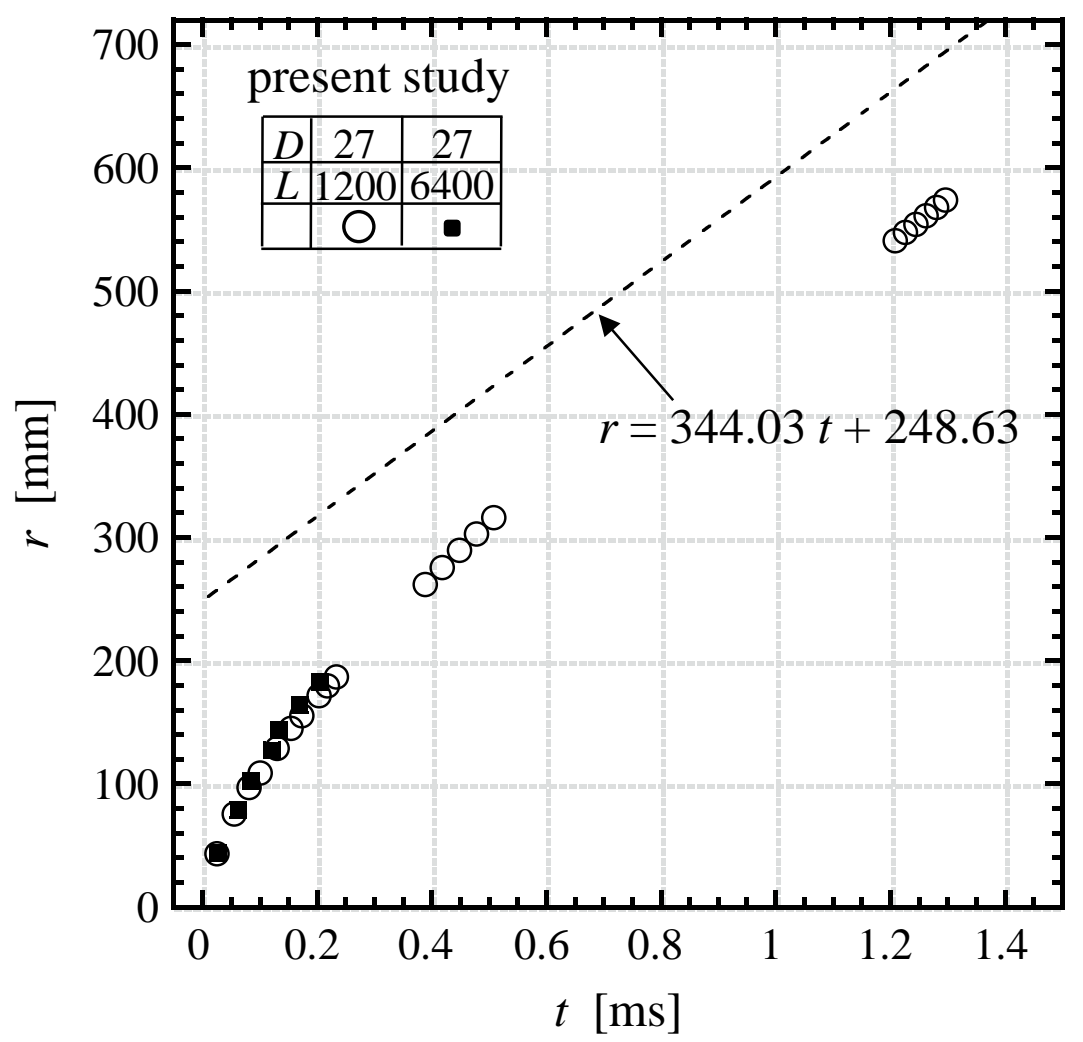

Fig. $11 r$-t diagram (near the tube open end)

( $D[\mathrm{~mm}]$ : tube diameter, $L[\mathrm{~mm}]$ : tube length) 


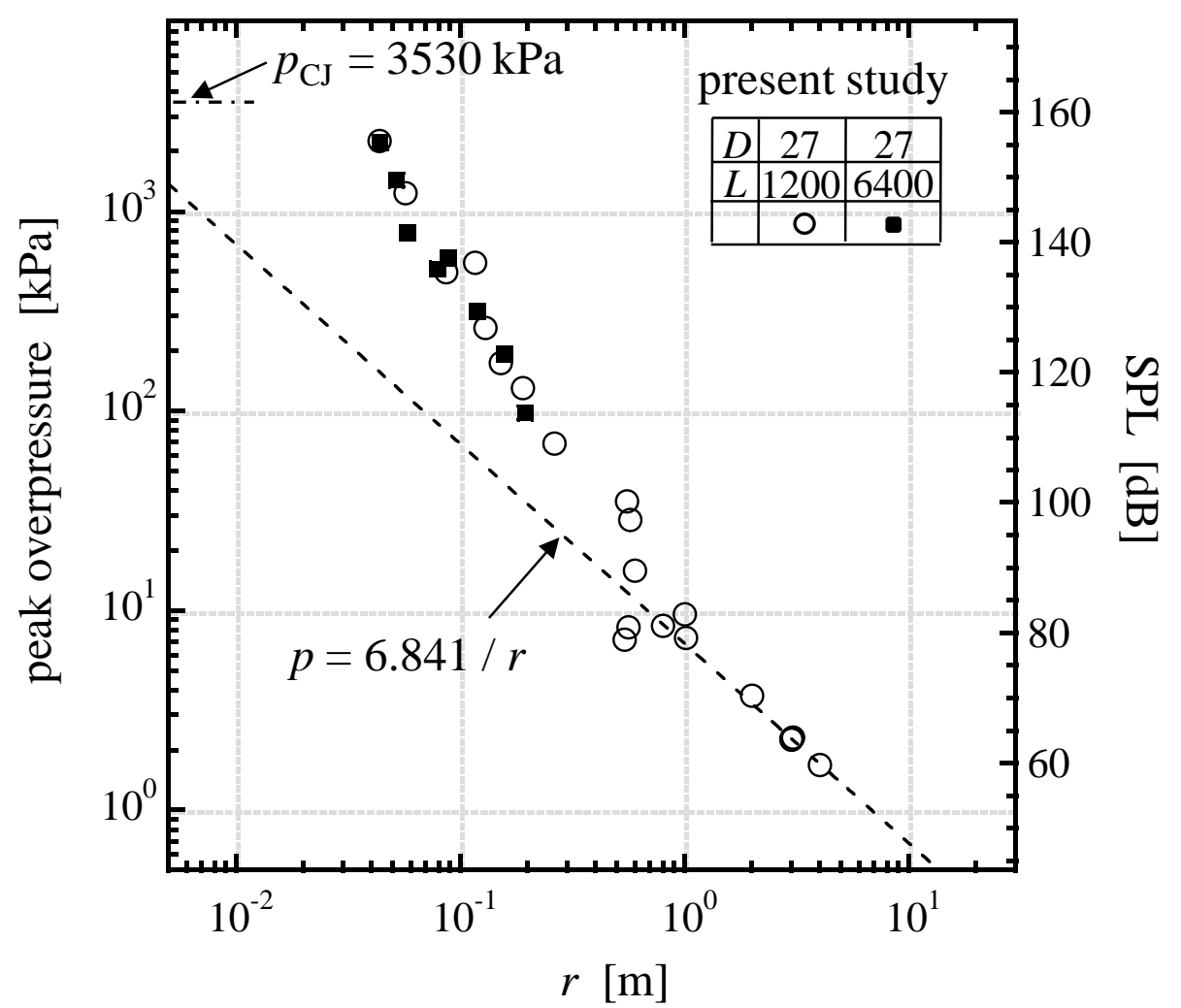

Fig. 12 Relationship between the peak overpressure and the distance (near the tube open end)

( $D$ [mm]: tube diameter, $L[\mathrm{~mm}]$ : tube length) 


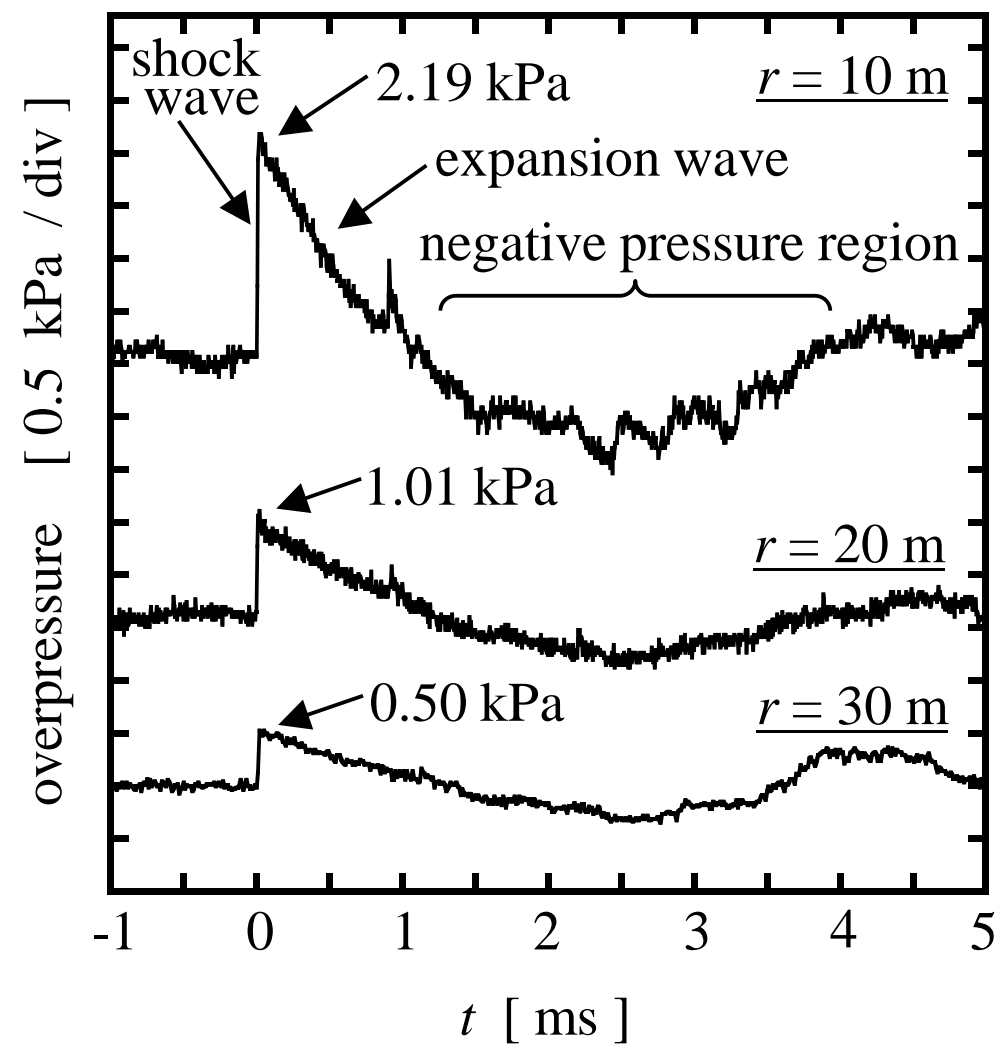

Fig. 13 Overpressure histories (Shot 13, 14, 15: $r=10,20,30 \mathrm{~m}$ ) 


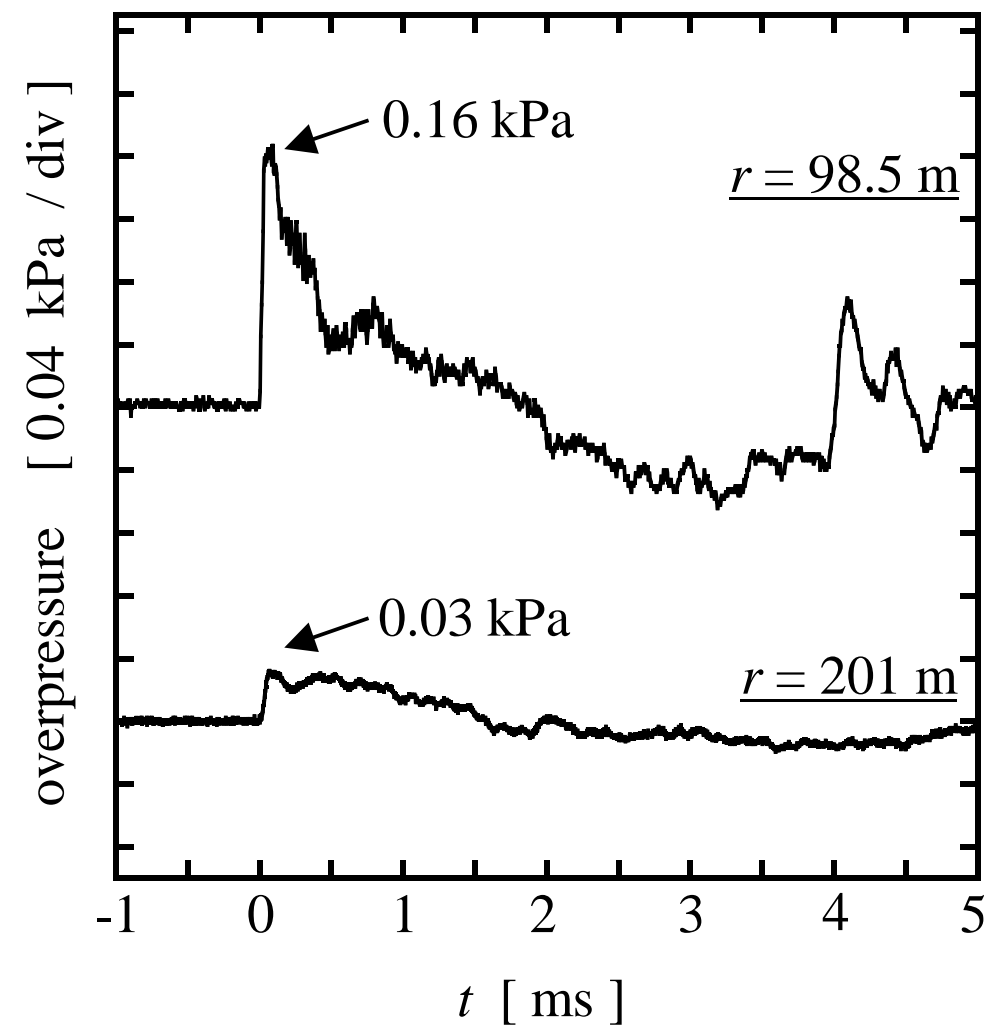

Fig. 14 Overpressure histories (Shot 16, 17: $r=98.5,201 \mathrm{~m}$ ) 


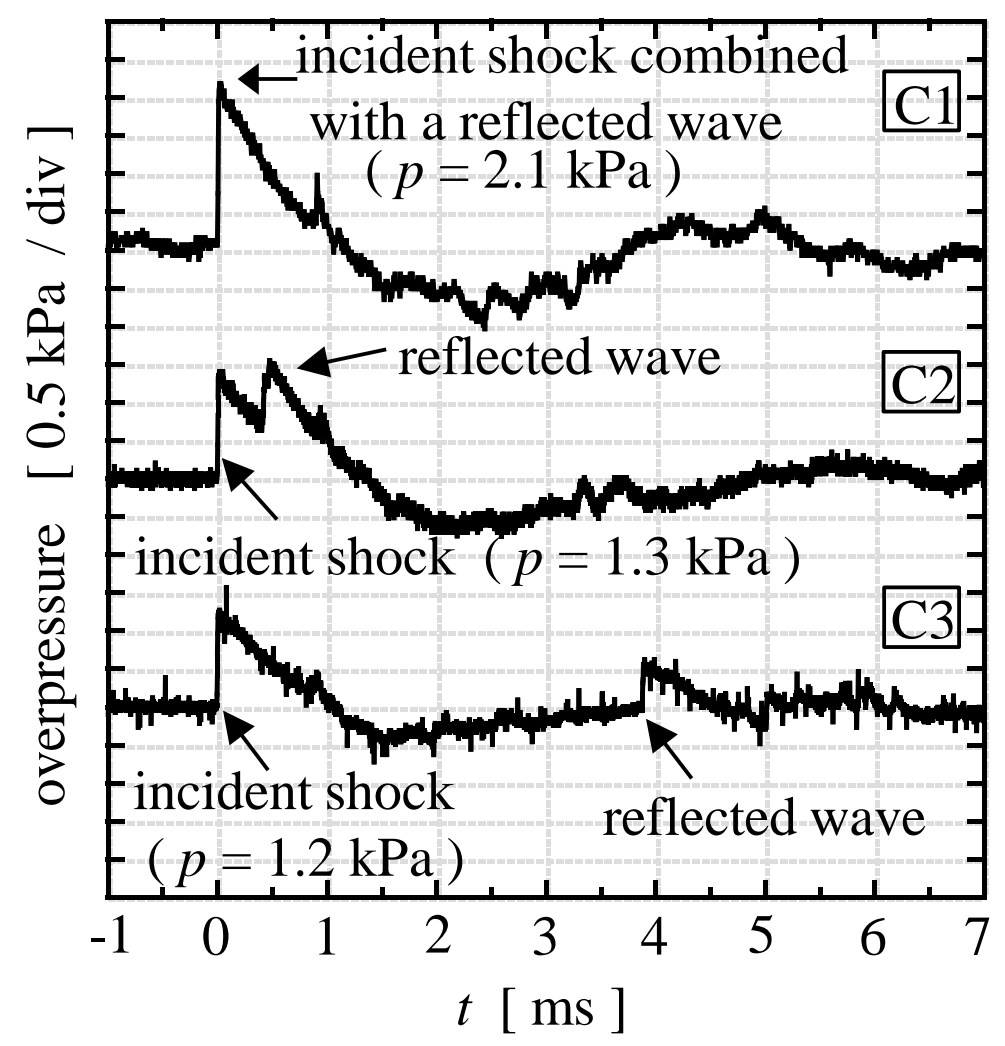

Fig. 15 Overpressure histories with various $h_{\mathrm{t}}$ and $h_{\mathrm{p}}$ (C1: Shot 13, C2: Shot18, C3: Shot19, $r=10 \mathrm{~m}$ ) 


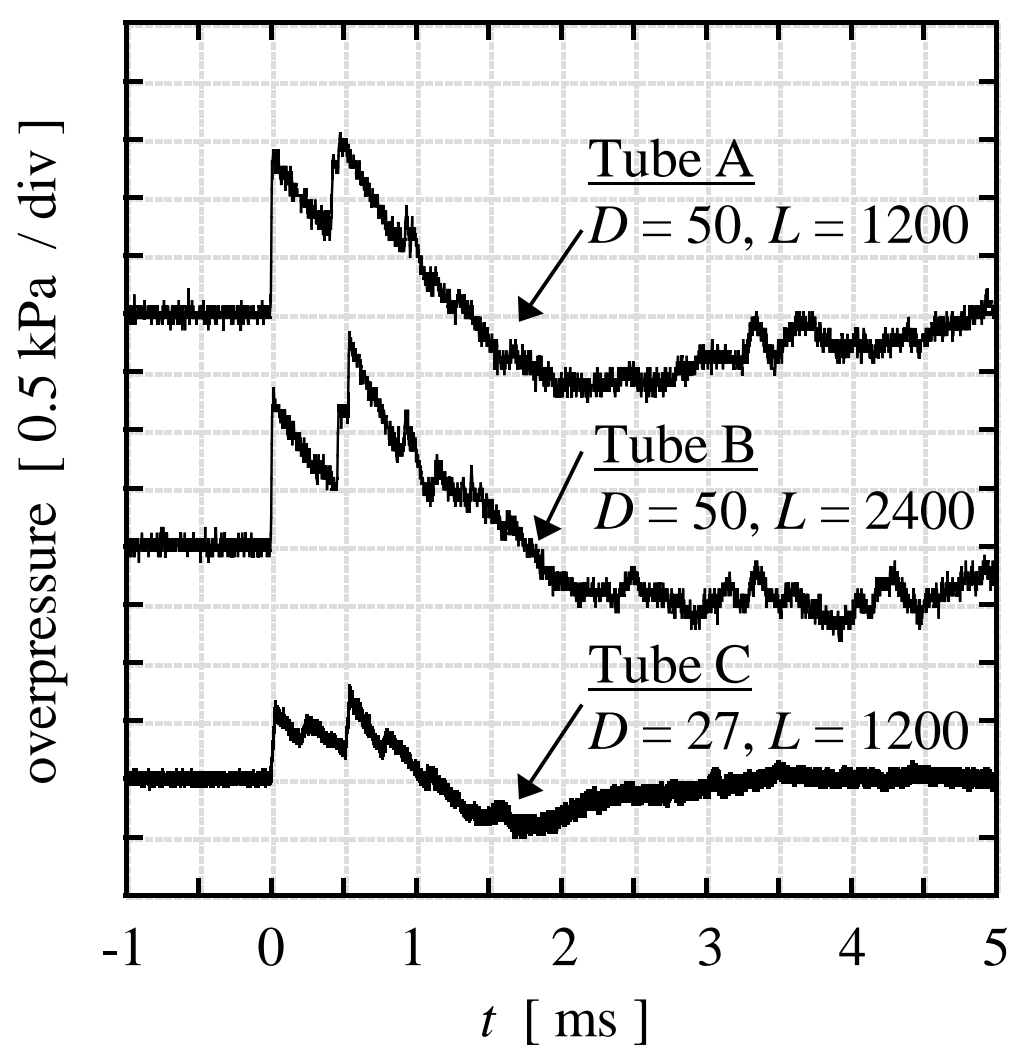

Fig. 16 Overpressure histories with varied $D$ and $L$ (Tube A: Shot 18, Tube B: Shot 20, Tube C: Shot 21, $r=10 \mathrm{~m}, D[\mathrm{~mm}]$ : tube diameter, $L[\mathrm{~mm}]$ : tube length) 


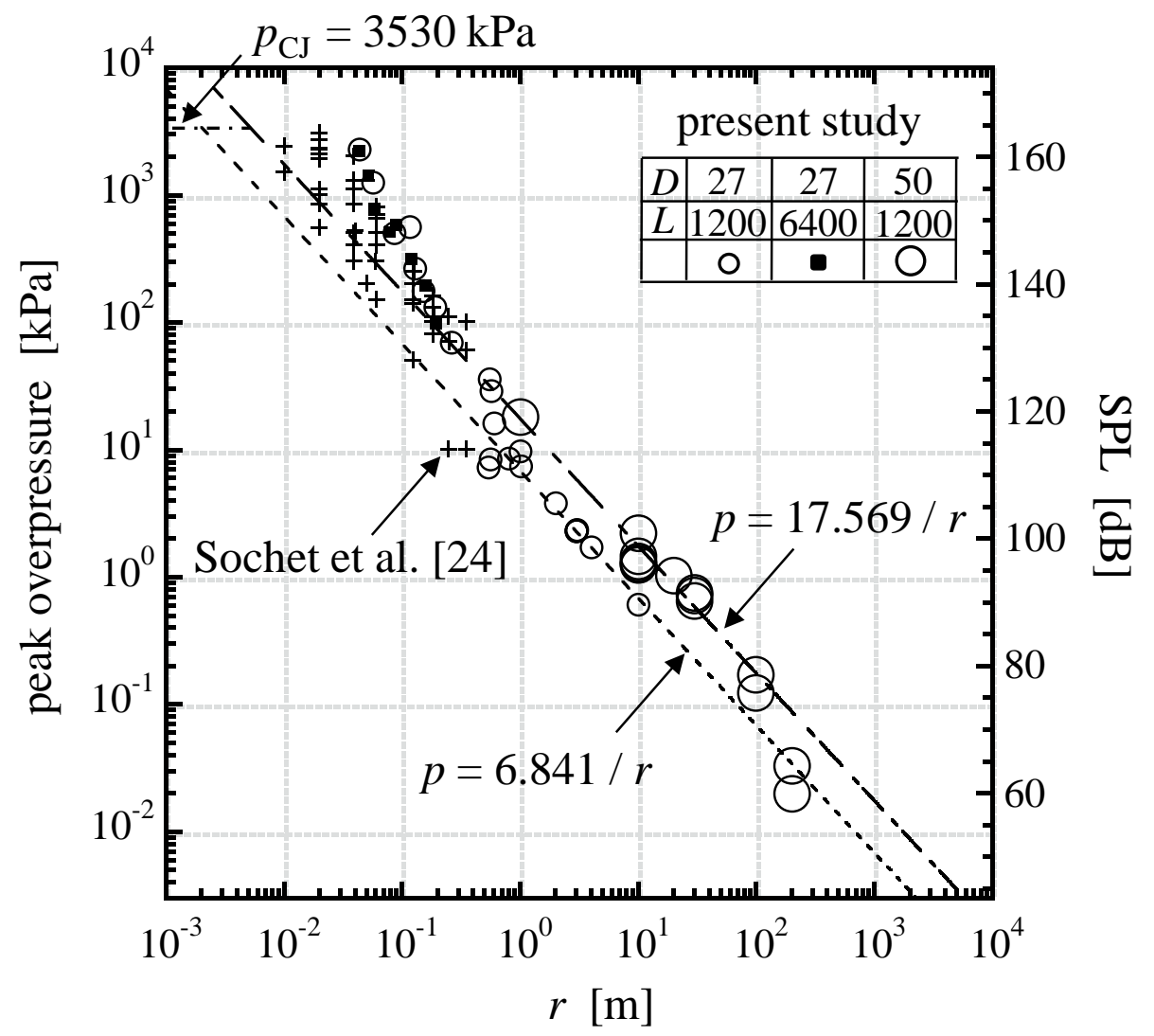

Fig. 17 Decay of the peak overpressure depending on the distance from the tube open end ( $D[\mathrm{~mm}]$ : tube diameter, $L[\mathrm{~mm}]$ : tube length) 


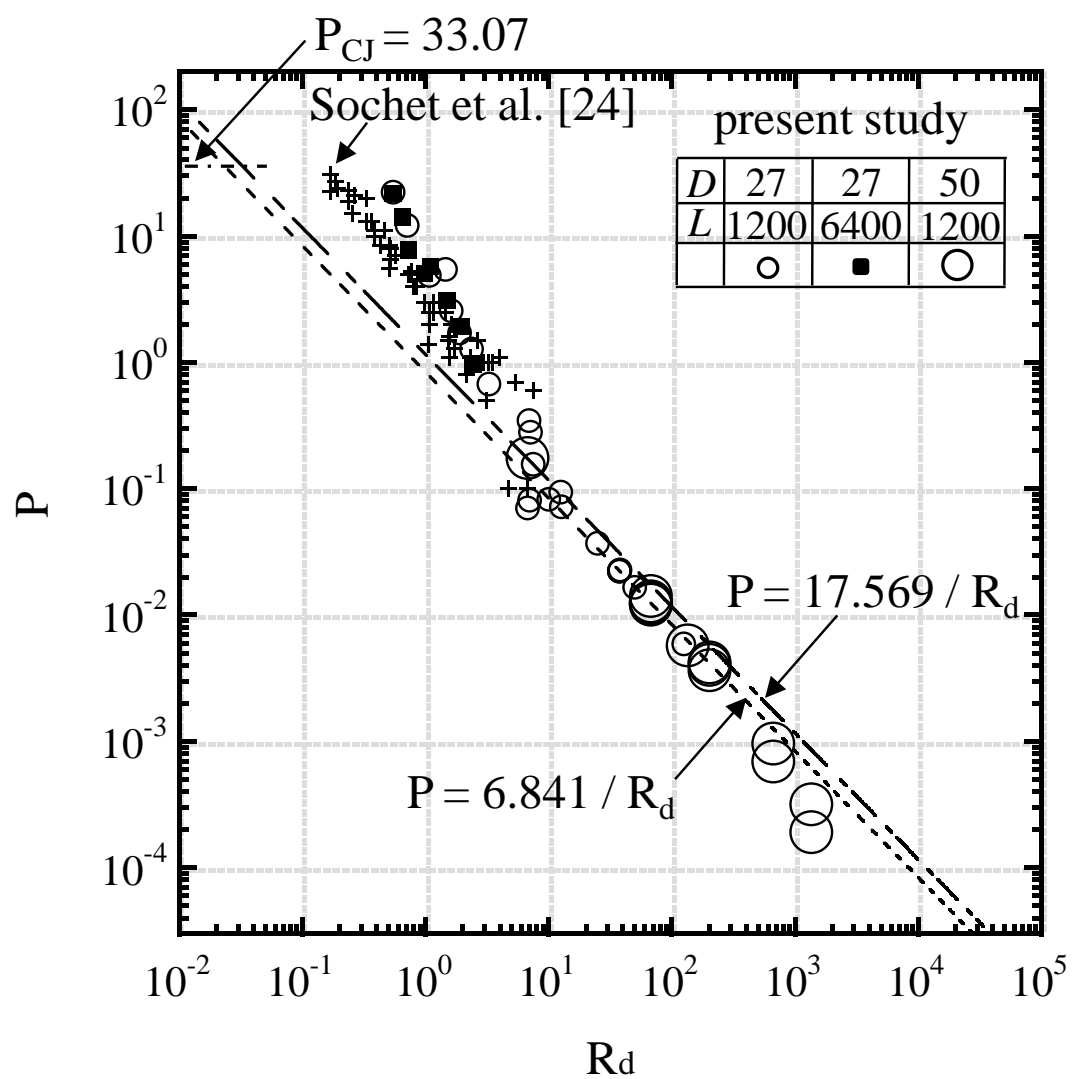

Fig. 18 Decay of the normalized pressure depending on the normalized distance from the tube open end ( $D[\mathrm{~mm}]$ : tube diameter, $L[\mathrm{~mm}]$ : tube length) 


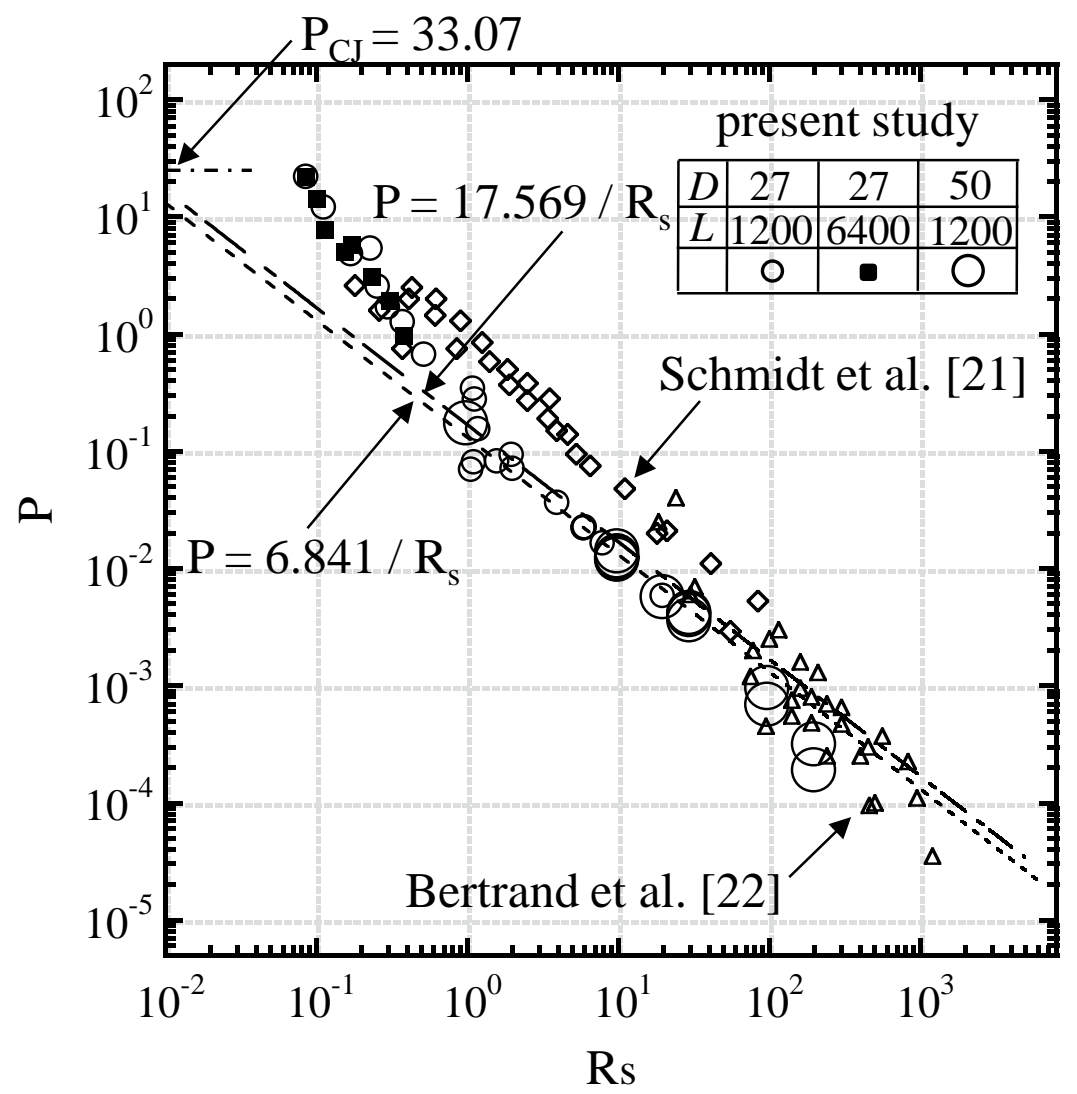

Fig. 19 Comparison of detonation tube experiments (our results and those of Sochet et al.) with shock tube experiments by Schmidt et al. and Bertrand et al. ( $D$ [mm]: tube diameter, $L$ [mm]: tube length) 